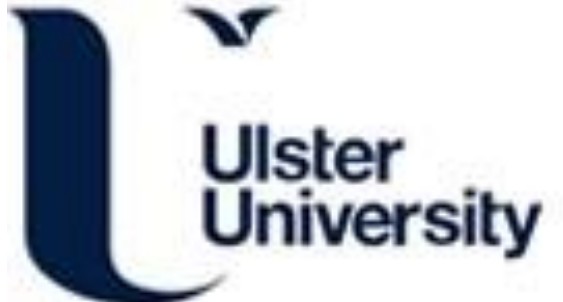

\section{Most promising flexible generators for the wind dominated market}

Vorushylo, I., Keatley, P., \& Hewitt, N. (2016). Most promising flexible generators for the wind dominated market. Energy Policy, 96, 564-575. https://doi.org/10.1016/j.enpol.2016.06.037

Link to publication record in Ulster University Research Portal

\section{Published in: \\ Energy Policy}

Publication Status:

Published (in print/issue): 30/09/2016

DOI:

10.1016/j.enpol.2016.06.037

\section{Document Version}

Author Accepted version

\section{General rights}

Copyright for the publications made accessible via Ulster University's Research Portal is retained by the author(s) and / or other copyright owners and it is a condition of accessing these publications that users recognise and abide by the legal requirements associated with these rights.

\section{Take down policy}

The Research Portal is Ulster University's institutional repository that provides access to Ulster's research outputs. Every effort has been made to ensure that content in the Research Portal does not infringe any person's rights, or applicable UK laws. If you discover content in the Research Portal that you believe breaches copyright or violates any law, please contact pure-support@ulster.ac.uk. 


\title{
Most promising flexible generators for the wind dominated market
}

I. Vorushylo ${ }^{1}$, P. Keatley, NJ Hewitt

\begin{abstract}
The intermittent nature of wind power and other forms of variable renewable energy requires complementary dispatchable flexible generators in order to guarantee the efficient, reliable and secure operation of electricity systems. The most popular solution to date has been peaking plant, usually in the form of open-cycle-gas- turbines (OCGT). Energy storage technologies have so far been considered too expensive, however technology development, as well as challenging renewable targets could potentially make storage economically viable. Although new advanced flexible combined-cycle gas turbines (CCGT) have been developed by some manufacturers, they have not yet been investigated in electricity market models. This paper describes a techno-economic assessment of the most suitable flexible technologies for the wind-dominated all Ireland electricity market (the Single Electricity Market (SEM)). The analysis is conducted by considering the impact of a series of policy scenarios which are compared in an electricity market model. The comparison is quantified using three primary metrics: technical benefits to the system, economic advantages to the consumer and investment viability. Modelling results suggest that advanced CCGT and energy storage solutions are the most advantageous, however they need strong governmental support to attract potential investors and guarantee deployment in the market.
\end{abstract}

Key words: energy storage, peaking generators, flexible advanced CCGT, Single Electricity Market, flexible generators, wind dominated market.

\section{Introduction}

\footnotetext{
${ }^{1}$ Centre for Sustainable Technologies, School of the Built Environment, Ulster University, United Kingdom BT37 0QB, i.lytvyn@ulster.ac.uk tel.:+44(0)2890368568 fax: +44(0)2890368239
} 
In order to diversify energy supply, reduce greenhouse gas (GHG) emissions and to promote a lowcarbon economy, many countries have implemented challenging targets for integrating variable renewable energy (VRE) technologies such as wind and solar power into national systems. For example, the European Union, along with the governments of the United Kingdom, Northern Ireland and the Republic of Ireland have set ambitious targets both for the reduction of GHG emissions and the proportion of energy demand to be served by renewable sources. Because it is mature and economically competitive, and because of the exceptional resources available, onshore wind power is the foremost VRE technology proposed to meet these targets. The governments of the Republic of Ireland and Northern Ireland (hereafter Ireland) have committed to serve $40 \%$ of demand with renewable energy in the all-island Single Electricity Market (SEM) and aim to facilitate the instantaneous penetration of up to $75 \%$ of load by non-synchronous power (NSP) by 2020 (DCNER, 2009), (DETINI, 2010). Given the near absence of hydro and the relative isolation of the Irish power system, these high targets make it perfect case study for the investigation of potential for flexible technologies in accommodating high levels of wind energy.

Integrating such high levels of VRE into a system built predominantly around large baseload generators has already resulted in significant levels of off-design operation for thermal plant and curtailment of VRE generation (Market Monitoring Unit, 2010), (Keatley et al, 2013), (Troy, 2010). The most common solution to the variability management problem to date has been the use of peaking generators like OCGTs. These have been favoured by investors due to their relatively low capital cost, flexibility and well-understood construction and operating processes. OCGTs are the only flexible generation technology which is expected to join the market by 2023, according to the latest Generation Capacity Statement report (Eirgrid, SONI, 2014). However, the high operating costs, low efficiency and consequently high GHG emissions of OCGTs have prompted the consideration of alternative, more efficient and less polluting forms of variability management for the future.

Recently, leading producers of thermal plant have announced the development of new advanced CCGTs, which are expected to be fast, flexible and highly efficient in cyclic operation. These units, 
designed to meet the need for flexible dispatchable generation in high VRE-penetration scenarios, will be available for the commercial deployment from 2015 (Probert, 2011). However, no installations of such generators have as yet been proposed or investigated for the SEM.

Grid-scale energy storage has also been proposed as a means to manage the increased variability of net load when high levels of non-dispatchable VRE are integrated into power systems (Edmunds et al, 2014), (Heide et al, 2011). Until now the main barriers to more widespread deployment of energy storage systems have been their high capital costs and, in the case of grid-scale systems such as pumped hydro and compressed-air energy storage, specific geographical requirements.

Previous studies on the deployment of centralised energy storage systems in the SEM concluded that there were potentially significant benefits in terms of reduced wind curtailments (Mullane, 2009), carbon emissions and spot prices, and increased security of supply. Connolly (Connolly et al, 2010) indicated highly favourable geographical sites for the building of pumped hydro systems, whilst the Triassic bedded salt formations in the north east of Ireland are promising for construction of compressed air energy storage (CAES) (Evans et al, 2006). Nyamdash et al. concluded that energy storage systems become viable options only with a great uncertainty in the system, e.g. wind power penetration of $50 \%$ and higher (Nyamdash et al, 2010). High capital costs are expressed as the major barrier for energy storage technologies installations in a number of studies (Connolly et al, 2012), (Foley, Díaz Loberaa, 2013), (O’Donnell, 2009), (Foley et al, 2015), (Tuohy, 2011).

Demand side response is another option to manage wind variability, which includes a wide range of possible solutions, owned and managed by final consumers. Demand side electric or thermal energy storage, smart meters and electric vehicles are among the most popular solutions being discussed in the scientific literature today. Implementation of demand response is not considered in this paper as it is a discrete area of research, which requires separate analysis, including the impact of human behaviour on the use and operation of demand-side technologies. This paper considers the requirement for optimal flexibility from the market point of view, although the potential contribution of demand side response replicates that oflarge scale energy storage as they have the same aim; to shift energy demand from 
periods of low electricity prices or high wind availability to periods of high prices and low wind availability.

It is evident that selecting the optimal solution to the variability management problem is not a straightforward process. Different studies give different answers to the question of the most technically and economically efficient options. The primary goal of this paper therefore is to make a comparative analysis of the most appropriate technologies to be deployed in the SEM, in terms of technical advantages for the system, financial viability for the investor and economic benefits for the consumer.

The research for this paper arose from the SPIRE (Storage Platform for Integration of Renewable Energy) project, which aims to quantify the potential for energy storage in the SEM. Analysis of historical electricity market operation shows that regulatory framework, market factors and operating characteristics have a significant impact on the profitability and overall viability of any generating unit. Analysis is therefore based on a model of the SEM developed with Plexos electricity market simulation software, which evaluates which flexible units (OCGT, CCGT or storage) are most likely to be scheduled to maintain system security and complement VRE, and to assess their potential profitability and consequent investment viability.

The modelling is focused on two time horizons: 2020 (with a renewable energy target of $40 \%$ (DCNER, 2009), (DETINI, 2010)) and 2030. As government targets for VRE generation have not yet been established for post-2020, 2030 is used as an indicative timeframe with two scenarios for renewable energy penetration, reflecting high and low levels of progress with respectively $45 \%$ and 52 $\%$ of electrical energy demand served by VRE as assumed by the SEM committee in its studies (SEM Committee, 2014).

Future market scenarios are developed from an extensive review of policy literature regarding SEM development, and possible alternative scenarios are suggested by the authors.

\section{Modelling methodology}




\subsection{Market model}

In order to analyse and compare the technical and economic characteristics of different flexible generators it is necessary to create a market model which is able to replicate SEM trading arrangements and is flexible enough to simulate a range of scenarios and market strategies. Plexos software was chosen for the design and simulation of the SEM model. This is one of the leading simulation tools for modelling aspects of electricity markets including investment planning, risk assessment, energy storage optimisation, electricity price forecasting and others (Energy Exemplar, 2010), (Bianco et al, 2015). The regulatory authorities of the SEM utilise Plexos for the market performance simulation and assessment, and investigation of market operation strategies (CER, NIAUR, 2012).

A schematic representation of the SEM model in Plexos is presented in Figure 1. The SEM is a mandatory gross pool market with two interconnection links to the Great Britain market with a total capacity of $1 \mathrm{GW}$. The Plexos model of the SEM therefore consists of the two regions: the SEM and GB markets, connected by two links representing the Moyle and East-West interconnectors. The SEM region is simulated with a detailed representation of all available generation units in the market in order to replicate spot price settlement, while the GB region has a simplified structure in order to reflect only import to and export from the SEM. Under current SEM market rules, all generators submit complex bids into the market which reflect short-run marginal costs (fuel and carbon costs, variable operational and maintenance costs) and exclude any fixed costs or profit components (CER, NIAUR, 2011). Spot price is based on an unconstrained market and is defined by the costs of the marginal unit that meets system demand for every half hour period. Spot price and unit commitment is defined by chronological market optimisation using a mixed integer algorithm based on the economic and technical characteristics of individual power plants. The objective function is total system costs minimisation.

The GB region is represented by a generation stack model, where all power generators are grouped by fuel type and efficiency characteristics. The GB market price is optimised separately with 
implementation of a long-run-marginal cost (LRMC) model where capital, fixed operational costs and profit components are allocated during the year in proportion to the available capacity margin (higher for the periods with a relatively tight capacity margin and lower for periods with excess capacity).

\subsection{Model validation}

The Plexos model was validated against historical data in order to ensure that it accurately reflects the conceptual market operation and is able to fulfil research objectives.

Validation was performed by comparing the historical outcomes of the real market with the results for the Plexos SEM model for the period January 2008 - October 2009. All model input parameters (available generators, their technical characteristics, variable operational and maintenance costs (VO\&M), demand profile, wind power output, etc.) were drawn from historical data (CER, NIAUR, 2012). Spot fuel prices were the same as those used by the Regulatory Authorities (RAs) for market monitoring (Platts, n.d.).

The objective function of the Plexos model is minimisation of the total system costs, which represents all costs required to meet system demand. Comparison of this model output with historic figures reflects how well market simulation was performed.

Plexos simulation outcomes (Table 1) fall within acceptable deviations from the historical data. The total energy market value is underestimated for around $6 \%$ for 2008 and $4 \%$ for 2009 . Validation tests show that the Plexos model provides an accurate representation of SEM.

\section{Future SEM market model}


The construction and validation of the current SEM model was presented in the previous section. The modelling methodology for the future SEM model follows the steps presented in Figure 2 and is described in the section below.

\subsection{Future SEM operation}

At the moment, the SEM operates as a mandatory pool with central dispatch and ex-post final settlement. However, in order to comply with European legislation, the SEM has to implement substantial changes in market design in order to adhere with the European Target Model (SEM Committee, 2014). These rules will require national markets to conform to certain criteria for a range of time horizons (forward, day-ahead, intraday) in order to build a functioning internal European energy market. In the case of the SEM, whose costs are settled on an ex-post basis, it will be necessary to establish market trading in line with the new timeframes.

The final modifications to the SEM design have not yet been decided or implemented, however changes must be in force by the end of 2017. In the interim, the SEM Committee has proposed a Mandatory Centralised Market structure for Day-Ahead, Intra-day and Balancing Markets. It also proposes to keep capacity remuneration mechanism (CRM) (SEM Committee, 2014). It is intended that the proposed market design will retain the strength of the current SEM and more closely aligns it with the EU Target model. However, given the major uncertainties surrounding the new market arrangements, the modelling for this study will reflect the most efficient operation of the current unitbased, gross-pool structure.

The real efficiency of the future SEM will depend on many factors including the bidding strategy of market participants, level of competition and market liquidity. It should be recognised that objectively estimating and modelling the influence of such factors is difficult in long-term modelling. In order to reflect harmonization in trading with neighbouring markets, simulations incorporate unconstrained interconnector operation. This means that the full capacity of interconnectors is available all the time, 
and import/export flow is based on price arbitrage between neighbouring markets. In contrast, efficient interconnector trading between the SEM and GB has historically been significantly restricted by various market factors (Vorushylo Lytvyn, Hewitt, 2013). The authors' modelling approach reflects optimal SEM operation and the most efficient utilization of interconnection capacity.

\subsection{Scenario development}

The wind power scenario for the 2020 market reflects government targets to achieve $40 \%$ of electricity demand from renewable energy, which requires an estimated $4700 \mathrm{MW}$ of wind capacity. Renewable energy targets for the 2030 market are not established yet, therefore assumptions are made to reflect rapid and slow progress in renewable energy deployment, in line with the projections of the SEM committee which assumes $52 \%$ and $48 \%$ penetration of renewable energy by 2030 (SEM Committee, 2014).

As previously mentioned, thermal generators are the current investment preference, and there are no firm plans for investment in storage. Two future market modelling categories have been developed: "Thermal Generators" and an alternative "Energy Storage" group of scenarios.

According to the latest transmission system operators' (TSO) report, three new OCGT units (with a total capacity of circa $300 \mathrm{MW}$ ) and two additional CCGTs (with a projected capacity of $450 \mathrm{MW}$ and 431 MW each) have signed connection agreements (Eirgrid, SONI, 2014). However, the TSOs expect that only part of this total capacity will be commissioned. Therefore only one 445 MW CCGT and one 98 MW OCGT are included in the generation fleet for 2023 (Eirgrid, SONI, 2014).

Four "Thermal Generators" scenarios were developed, incorporating new OCGTs and CCGTs ranked by technology type and likelihood of realisation:

- The NIFG (no investments in flexible generation) model - consists of all current generation units still available in 2020 and 2030 respectively, new renewable energy generators, plus 
one new conventional CCGT unit by 2020 and one further conventional CCGT unit by 2030 in order to maintain capacity margins. This model does not consider any further investments in any flexible type of generation.

- BaU (business as usual) model - includes the portfolio of the NIFG model plus new OCGT units with a total installed capacity of $300 \mathrm{MW}$ by 2020 and $400 \mathrm{MW}$ by 2030 . This scenario reflects the TSOs' current assumptions, suggesting that new OCGT units will be deployed to address variability management.

- Advanced CCGT model - this model consists of the generation portfolio of the NIFG model plus one additional CCGT unit, with operating characteristics which represent flexible advanced CCGT technology.

- Advanced CCGT model reduced - this model is developed for the 2030 market only. It aims to investigate whether the advanced CCGT generator is able to fulfil the requirements of both the new conventional CCGT and new OCGT generators. This portfolio comprises only one new conventional CCGT (instead of two) and one advanced CCGT unit.

Increasing levels of both consumer demand and VRE capacity, combined with the retirement of older thermal plant, will necessitate the deployment of flexible generators in order to guarantee security of supply. Because a substantial proportion of plant retirements by 2030 will comprise existing peaking plants, the NIFG scenario is highly unlikely to be realized by 2030. It is therefore presented for indicative purposes only. To make the 2030 scenarios more directly comparable with each other, installed capacities for new generators are slightly modified: installed capacity for new OCGT units is 100 MW (instead of $98 \mathrm{MW}$ ); installed capacities for the second conventional CCGT unit and the advanced CCGT unit are 400 MW each (instead of 440 MW and 500 MW respectively).

The "Energy Storage" group of scenarios considers the deployment of energy storage systems as an alternative to conventional generation. Four scenarios assess the market performance of $100 \mathrm{MW}$ to $400 \mathrm{MW}$ of new energy storage technologies. 
All scenarios are also split into two subcategories in 2030 representing rapid and slow progress in renewable energy deployment beyond 2020. Generation portfolios for developed scenarios are summarized in table 2.

\subsection{Technical characteristics of new generators}

The technical characteristics of new thermal generators are presented in Table 3. Characteristics of new CCGT and OCGT units are based on the operational parameters of typical modern generators and recently installed units in the SEM (CER, NIAUR, 2012).

The Advanced CCGT plant characteristics are based on the General Electric Flexi50 CCGT model (General Electric, 2011). The leading producers of power generation technologies have developed flexible CCGT units with fuel efficiency exceeding $60 \%$ and response times which complement wind generation dynamics. For example, Alstom's KA26 model claims to achieve $350 \mathrm{MW}$ output within 15 minutes, while the FlexEfficiency50 model from General Electric can ramp its output rate at 50 MW/min (Hummel et al, 2013), (Probert, 2011).

Energy storage technologies are characterised by four main parameters: power rating, storage rating, time response and efficiency. Power rating varies between $100 \mathrm{MW}$ and $400 \mathrm{MW}$ in increments of 100 MW. Assumed power ratings are equivalent to the installed capacities of other flexible technologies implemented in the "Thermal Generators" scenarios. Energy rating is assumed to be $4 \mathrm{GWh}$ in all storage scenarios, which is enough to provide $10 \mathrm{~h}$ of operation for a $400 \mathrm{MW}$ unit and $40 \mathrm{~h}$ for a 100 MW unit. Storage efficiency of $75 \%$ is based on an average value for large-scale application characteristics. Typical time response ratings for most storage applications are of the order of several minutes. Due to the 30 minutes resolution in the SEM, this characteristic does not influence unit commitment decisions and is therefore omitted in the Plexos model. 
Particular storage technologies are not selected at this stage. Technology neutrality for initial modelling allows for the optimization of capacity. Technology selection is performed later via costbenefit analysis based on capital cost requirements and profitability assessment.

Wind energy is included through an externally produced profile. In order to capture the spatial and temporal resolution of wind power, it has been produced by the linear extrapolation of the 2008 regional wind profile (CER, NIAUR, 2012), taking into account future wind energy targets (40\% for 2020, 48\% for SP and $52 \%$ for RP scenarios) and regional wind constraints (EirGrid, SONI, 2014), (Gariggle et al, 2013). The wind power profile is presented at one hour time resolution.

Other renewable technologies (e.g. solar PV, private wind turbine, small-scale combined heat and power and hydro power stations) are expected to deliver relatively insignificant contributions towards future renewable targets in comparison with wind power. They are induced into the model as embedded generation (negative demand) and produced by linear extrapolation of current profile into their future projections (Eirgrid, SONI, 2015).

\subsection{Macroeconomic parameters/assumptions}

The following macroeconomic parameters have been utilised in the Plexos model for future market operation;Fuel and carbon prices are based on a DECC central fuel price assumptions and are presented in Table 4 (DECC, 2013).

SEM demand is based on quadratic extrapolation of historic system demand on system operators' projections for 2020 and 2030 (EirGrid, SONI, 2014), (SEM Committee, 2014), and is presented in table 5 .

The GB market portfolio for 2020 and 2030 is based on the National Grid UK Future Energy scenarios (National Grid, 2014). Also, the 2030 market, similar to the SEM model, develops Rapid and 
Slow Progress scenarios based on "Gone Green" and "Slow Progression" scenarios of National Grid respectively (National Grid, 2014). The key assumption regarding the GB future market generation profile is that, as with the situation in the SEM, renewable energy targets will be achieved, with the installation of circa $26.3 \mathrm{GW}$ of wind energy by 2020 . For the 2030 market Rapid Progress is assumed to result in $28 \%$ of energy demand served by VRE and Slow Progress by a $23 \%$ contribution from renewables.

\subsection{Cost-benefit analysis}

The last stage of the proposed methodology is a cost-benefit analysis of future flexible generators in the wind-dominated SEM. It is based on a comparison of the costs of building and operating flexible generators, with the potential advantages of technology profitability and socio-economic benefits to energy market consumers. Potential technology profitability and socio-economic benefits will be derived from the simulation and represents profits frominfra-marginal rent (the difference between spot and bid prices) on a yearly basis.

The annualised costs of building and operating flexible generators are defined by the following formula:

$$
\text { Yearly charges }=\frac{c \times i(1+\mathrm{i})^{\mathrm{Y}}}{(1+\mathrm{i})^{\mathrm{Y}}-1}+\mathrm{FO} \& M
$$

Where $\mathrm{c}=$ capital costs estimation; $\mathrm{Y}=$ economic life of the project; $i=$ hurdle rates $($ assumed $7.8 \%$ in accordance with (DECC, 2013)), FO\&M = fixed operational and maintenance costs.

Assumptions of the total capital and recurring costs of new flexible generators are presented in tables 6 and 7 .

Investment costs for energy storage technologies vary considerably. Investment requirements used in this study consider the most technically mature types of solutions (table 7) (Gatzen, 2008), (Xi. Luo et al, 2015), (Zhao et al, 2015), (Strbac et al, 2012), (Deane et al 2010). 
To summarize, the market model developed in this section aims to represent a future winddominated SEM under the following conditions;

- without any additional flexible generators ("NFIG" model),

- with peaking generators ("BaU” model),

- with the introduction of advanced flexible CCGT solutions ("Advanced CCGT" and “Advanced CCGT minus” models)

- Energy Storage models 1 - 4 (100, 200, 300 and 400 MW capacity)

Technical, economical and investment analysis of modelling results for these scenarios gives us a picture of the optimal flexible solution for the wind dominated SEM.

\section{Modelling results}

The final modelling results have been divided into four main categories:

- Technical benefits for the operation of baseload units;

- $\quad$ Economic advantages for consumers;

- Cost-benefit analysis of new flexible generation;

- Sensitivity analysis.

\subsection{Technical benefits for the operation of the future SEM}

This section focuses on the potential future impact of wind power on baseload generation and how new flexible technologies are capable of maintaining system stability.

The modelling results suggest that levels of energy generated by baseload and mid-merit generators will be significantly reduced in comparison with current levels. Their generation is displaced by wind 
power with the support of new and existing peaking generators. Moreover, despite a reduction in energy generation by baseload and midmerit units, their operational response is considerably increased, while the increasing installation of flexible generation capacity reduces this impact. Increasing numbers of start-ups for base-load units are directly related to increased maintenance costs (Keatley et al 2013). Fig. 3 compares energy generation and number of start-ups for existing baseload and midmerit gas and coal generators in 2020 with figures from November 2010 - November 2011.

Fig. 3 shows that Energy Storage 4 model results in the lowest level of start-ups for large thermal power plants. Identical results are obtained for the 2030 models with increased further contribution from VRE (fig. 4): total energy generation by baseload and mid-merit generators is further reduced, while their numbers of start-ups increase.

Deployment of 300MW - $400 \mathrm{MW}$ of energy storage significantly diminishes the impact of VRE on the cyclic operation of baseload generators, demonstrating considerably better results than other flexible technologies. The Advanced CCGT unit is the least advantageous solution among flexible generators from this point of view.

It is critical to note however, that because the market operation schedule is based, first of all, on economic principles (merit order), the most efficient generators are scheduled for baseload generation, regardless of their flexibility. Therefore, less flexible and efficient generators are utilised for the system flexible response requirements. Fig. 5 shows that because of its high fuel efficiency, the Advanced CCGT unit has one of the highest energy generation rates and among the lowest number of start-ups compared to other generators.

It should also be noted that scheduling optimization is based on an unconstrained approach which results in the most efficient market schedule notwithstanding transmission constraints and system reserve requirements. Transmission constraints in real market operation can influence the decision to run less efficient generators, sometimes even on a constant, baseload basis. This leads to a decrease in 
overall system flexibility, sub-optimal cycling of other units, increased numbers of start-ups and ramping duty of other generators, as well as wind power curtailments.

It can be concluded that an efficient 2020 market requires the support of flexible generators from a technical point of view. The Energy Storage models examined potentially deliver the greatest advantage in comparison with other flexible solutions by decreasing the level of cycling of baseload and mid-merit generators. In order to minimise the negative impact of VRE on the operation of baseload generators, appropriate market mechanisms should be investigated and developed in order to encourage flexibility in the market.

\subsection{Economic advantages to the electricity market consumers}

The economic characteristics of future market operation under the proposed scenarios for one full year of operation are presented in tables 8 and 9. As stated in the methodology, the model design reflects perfect market operation. Therefore, the economic results presented in this section should not be regarded as absolute or predictive, but considered as indicative, relative values to allow comparison of different scenarios. Also, as the model validation section shows, modelling results incorporate some level of uncertainty, however, as the main aim of this section is to compare scenarios for the same market model with the same assumptions applied, these uncertainties are omitted from the analysis presented below.

As can be seen from Table 8, all flexible solutions bring benefits to the operation of a future wind dominated market, however the Energy Storage 4 model is the most economically advantageous with circa $2.11 \%$ or $74 € \mathrm{~m}$ of total system cost savings when compared with the NIFG Model. The BaU Model is less advantageous, providing only $0.15 \%$ or $5 € \mathrm{~m}$ savings, although it should be noted that this scenario proposes only $300 \mathrm{MW}$ of new OCGT capacity, 100 MW lower than for the Energy Storage 4 or the Advanced CCGT scenarios. Additional runs of the BaU model with 400 MW OCGT 
showed total system cost savings of only $1 € \mathrm{~m}$ confirming that the BaU model is economically the least advantageous solution.

With an increased share of VRE (2030 models, Table 9) the BaU model with the OCGTs remains the least beneficial scenario, while the Advanced CCGT model demonstrates the best results from an economic perspective. The best of the energy storage scenarios was the Energy Storage 4 model, which demonstrates total system costs savings which are $0.4 \%$ and $0.20 \%$ lower than the Advanced CCGT model for the Slow and Rapid Progress scenarios respectively.

The economic benefits of the Advanced CCGT model (as shown in the technical analysis section), are mostly achieved by displacing less fuel-efficient baseload generation, whilst its flexibility attributes are not used extensively. Thus, the Advanced CCGT reduced model, which consists of only one new standard CCGT unit, shows system costs saving which are significantly lower in comparison with the Advanced CCGT model. These savings are also the lowest of all other modelling results for the Rapid Progress scenario. This result suggests that the existing SEM generation portfolio is relatively inefficient and requires new investment in efficient and technologically advanced generators. It may also be an indication that increased level of VRE penetration will critically require flexible generators, whilst retired or relatively old existing peaking plants will not be able to fully satisfy those requirements.

\subsection{Cost-benefit analysis of new generation}

A cost-benefit analysis of flexible generators was performed for 2020 and 2030 SEM operation.

Simulation results for the profitability of proposed flexible technologies achieved via infra-marginal rent (the difference of spot and bidding prices) are presented in Tables 10 and 11. 
From Tables 10 and 11 it can be seen that advanced CCGT units receive the highest level of profit, while OCGTs show limited profitability.

Cost-benefit analysis results for the suggested flexible solutions, based on annualised investment costs and potential profitability, are presented in Fig. 6 (2020) and Fig. 7 (2030).

Fig. 6 shows that only CCGTs are able to recover their investment costs through profit realized from infra-marginal rent. The relatively low capital costs of OCGT units are outweighed by their very limited profitability.

Among energy storage technologies, pumped hydro and CAES are the most viable, whilst redox batteries and hydrogen remain expensive solutions. Moreover, lifecycle greenhouse gas emissions for CAES and pumped-hydro energy storage are much lower than for advanced batteries or any fossil fuel generators when operated with high renewable penetration (Bouman et al, 2016), (Denholm, Kulcinski, 2004).

With increased renewables penetration (Rapid Progress scenario, Fig. 7 b) there is the potential for the most viable energy storage solutions to cover their annualised investment costs if provided capital costs do not reach their maximum level.

The capital costs of the most efficient pumped hydro or CAES solutions are primarily dictated by specific topographical and geographical site requirements. Ref (Connolly et al, 2010) concluded that the island of Ireland has exceptionally good geographical locations for siting pumped hydro installations. This study identified five potential technically suitable sites in Ireland with a combined capacity of $700 \mathrm{MW}$ and energy storage of $9 \mathrm{GWh}$. Salt deposits in the Larne area of Northern Ireland could potentially offer suitable locations for the installation of a CAES system (Evans et al, 2006). Therefore it is reasonable to assume that pumped hydro or CAES projects with low-to middle capital cost range could be realized. 
Despite the fact that the flexible solutions presented in Figs. 6 and 7 show a profit deficit in recovering their investment costs, two additional factors play an important role in their investment viability: capacity payments and ancillary services.

The priority dispatch of renewables and resulting decreased number of operating hours for thermal generators have already initiated the development of capacity payment mechanisms in many countries across Europe (Mastropietroa et al, 2015) in order to support generators and guarantee security of supply. Moreover, the SEM Committee has already established that there is a need to include CRM in the future SEM design (SEM Committee, 2014). Estimating the future value of capacity payments is not straightforward due to the changing market design priorities and the specific attributes of different capacity payments mechanisms. Nonetheless, this is potentially a major supportive instrument in the deployment of emerging flexible technologies (Cutter et al, 2014), (Hach, Spinlerr, 2014).

The second factor represents payments through ancillary services. At the moment such payments deliver a relatively small contribution to the profitability of power plants (SEM Committee, 2014). However, the increasing penetration of VRE has stimulated a reconsideration of ancillary services in the SEM (SEM Committee, 2014). In combination with capacity payments, ancillary payments could potentially eliminate any deficit in profitability for new storage generators.

Finally, it is crucial to indicate the overall socio-economic benefits which flexible generators could bring to the market, which are presented here as total system cost savings. The final cost-benefit analysis, including total system cost savings, is presented in Figs. 8, 9 and 10.

The final cost-benefit analysis shows that any deficit in recovering the investment costs of new flexible generators is overwhelmed by total system costs savings. The advanced CCGT units bring the highest socio-economic benefits to the market with the increased penetration of renewables (in the Rapid Progress scenario) and would probably be able to cover their investment costs through inframarginal rents. Energy storage systems were shown to be more beneficial than OCGTs, with the optimum capacity being $300 \mathrm{MW}-400 \mathrm{MW}$. 
Indicative system cost savings suggest that the overall contribution of flexible generators to the system is significant, and considerably exceeds investment cost requirements. Therefore these savings could be directed to supporting emerging flexible generation in order to deliver efficient market operation.

\subsection{Sensitivity analysis}

A sensitivity analysis was carried out to investigate changes in future market performance under a range of fuel price scenarios. Fuel price uncertainty makes profitability forecasts and investment decisions regarding choice of power generation technology difficult. In order to perform the sensitivity analysis assumptions for future commodity prices based on High and Low price scenarios from DECC projections were implemented into the 2030 SEM market models (table 12) (DECC, 2013).

Predictably, the sensitivity analysis indicates an increase in spot electricity prices for the high fuel price scenario and a decrease for the low fuel price scenario (Fig. 11).

Different levels of dependence on fossil fuels, as well as differences in overall portfolio structure between the GB and the SEM, leads to non-parallel changes in the generation profiles and profitability of flexible solutions (Fig. 12).

Fig. 12 indicates that energy storage technologies show the least sensitivity to changes in fuel prices, while peaking generators demonstrate the highest level of sensitivity. The Energy Storage $2-4$ portfolios demonstrate an increase in profitability in the Rapid Progress scenarios under both low and high fuel prices. 
In terms of providing certainty to consumers and system operators, energy storage technologies are the most stable and least risky solution under commodity price deviations, while peaking generators bring increased uncertainty to investors.

\section{Conclusions and Policy Implementations}

This paper investigates the potential for flexible generators in the future SEM wind dominated market, including: peaking plants (OCGT), new flexible CCGT generators, and energy storage systems. The simulation of the future SEM market model highlights the need for flexible generators to support system efficiency and stability. The model simulation without new investments in flexible generators demonstrated significant negative impact on the operation of baseload generators, as well as increases in electricity prices and total energy market values.

Energy storage systems can potentially be the most technically advantageous flexible generators, significantly mitigating the impact of wind power on the operation of baseload plants. They demonstrate the most stable profitability and consequently investment viability under commodity price deviations. From a simple economic point of view the advanced flexible CCGT is the most beneficial solution in stable commodity price scenarios. Advanced CCGTs have not yet been investigated for the SEM and demonstrate very promising potential for the future system operation, suggesting up to $3.2 \%$ reduction in total market value costs.

Despite the relatively high capital costs of energy storage systems they can recover their investment costs, and be economically efficient in high variability commodity price scenarios. In contrast peaking generators potentially would not cover their investment costs requirements.

The modelling results also indicate that the optimal parameters for energy storage solutions for the 2020 wind dominated SEM are 300 MW - 400 MW of installed capacity with 4 GWh of energy storage. The most likely technologies are pumped hydro or CAES. The existence of favourable 
geographical sites for both these technologies in Ireland suggests their potential viability with relatively low capital costs.

It is important to emphasise the key role of government in promoting the integration of flexible technologies. Potential investors in flexible generators will only be attracted to the market if capacity payment mechanisms and ancillary services payments send appropriate signals for new investment. Furthermore, in order to maximise the benefits of flexible technologies it will be necessary to expand mechanisms rewarding flexibility in the system. Under the current market optimisation regime, efficient generators are scheduled for baseload operation, whilst less efficient and flexible generators perform cycling operation in order to manage wind power and demand fluctuations. Potential system cost savings realized through flexible technologies could be directed to supporting mechanism for flexible generators while increasing electricity market efficiency compared to the business as usual case.

Investigation of the optimal secure operation of VRE-dominated markets is of prime importance for most European systems. The characteristics of the Single Electricity Market (limited interconnection, the near absence of hydro resources, and highly ambitious renewable energy targets), provide an exemplar for the management of challenges that other European markets will eventually face in order to successfully integrate very high levels of VRE. The methodology presented in this paper is therefore applicable to other electricity markets, which need to conduct a comprehensive analysis of the potential of flexible generators.

\section{Acknowledgment}

The authors gratefully acknowledge the support of the European Union INTERREG IVA programme through the Special EU Projects Body (SEUPB). We also express our gratitude to Energy Exemplar for the free academic Plexos license and its team for support with modelling issues, and to FICO for providing its Xpress solver for mixed integer programming. 


\section{References}

1. A. Foley, I. Díaz Loberaa. (2013). Impacts of compressed air energy storage plant on an electricity market with a large renewable energy portfolio. Energy (57), 85-94.

2. A. Tuohy, M. O. (2011). Pumped storage in systems with very high wind penetration. Energy Policy, 39 (4), 1965-1974.

3. A.M. Foley, P.G. Leahy, K. Li, E.J. McKeogh, A.P. Morrison. (2015). A long-term analysis of pumped hydro storage to firm wind power. Applied Energy (137), 638-648.

4. Bouman E., Oberg M., Hetwich E.G. (2016), Environmental impacts of balancing offshore wind power with compressed air energy storage (CAES). Energy (95), 91-98

5. Denholm P., Kulcinski G.L., (2004)Life cycle energy requirements and greenhouse gas emissions from large scale energy storage systems, Energy Conversion and Management (45), 2153-2172

6. CER, NIAUR. (2011). Principles of Dispatch and the Design of the Market Schedule. Retrieved 2015 йил 09-January from

http://www.allislandproject.org/en/renewable_decision_documents.aspx?article=b94b7748-1faf41e3-975a-a0323d074eca

7. CER, NIAUR. (2012). Validation of Market Simulation Software in SEM to end 2013. Retrieved 2015 йил 09-January from http://www.semcommittee.eu/en/market_decision_documents.aspx?page=5\&article=1c2cbca7-b9fd4be2-bc5a-4449d017d544

8. D. Connolly, H. Lund, B.V. Mathiesen, E. Pican, M. Leahy. (2012). The technical and economic implications of integrating fluctuating renewable energy using energy storage. Renewable energy (43), 47-60.

9. D. Connolly, S. MacLaughlin, M. Leahy. (2010). Development of a computer program to locate potential sites for pumped hydroelectric energy storage. Energy , 35 (1), 375-381.

10. D. Heide, M. Greiner, L. Bremend, C. Hoffmanne. (2011). Reduced storage and balancing needs in a fully renewable European power system with excess wind and solar power generation. Renwable Energy, 36 (9), 2515-2523.

11. D.I Hach, S. Spinlerr. (2014). Capacity payment impact on gas-fired generation investments under rising renewable feed-in - A real options analysis. Energy Economics .

12. DCNER. (2009). National Renewable Energy Action Plan. Ireland. Retrieved 2015 йил 09-January from http://www.dcenr.gov.ie/

13. Deane J.P, Ó Gallachóir B. P, McKeogh E.J. (2010). Techno-Economic Review of Existing and New Pumped Hydro Energy Storage Plant. Dublin.

14. DECC. (2013). DECC Fossil fuel price projections. London: Crown Copyright.

15. DECC. (2013). Electricity Generation Costs. Retrieved January 9, 2016 from www.gov.uk/decc 
16. DETINI. (2010). Northern Ireland Strategic Energy Framework. Retrieved January 09, 2015 from https://www.detini.gov.uk/articles/strategic-energy-framework-2010

17. E. Cutter, B. Haley, J. Hargreaves, Ji. Williams. (2014). Utility scale energy storage and the need for flexible capacity metrics. Applied Energy, 124, 274-282.

18. Eirgrid, SONI. (2014). All Island Generation Capacity Statement 2014-2023. Retrieved 2015 09-January from http://www.eirgridgroup.com/site-

files/library/EirGrid/Generation\%20Capacity\%20Statement\%202014.pdf

19. Energy Exemplar. (2010). Leading the field in Electric Power Market Modelling. Retrieved 2015 йил 09January from http://www.energyexemplar.com

20. Evans D.J., Reay D.M., Relay N.J., Mitchell W.I., Busby J. (2006). Apprisal of undeground energy storage potential in Northern Ireland. Keyworth: Nottingham British Geological Survey.

21. E.V. Gariggle, J.P. Deane, P.G. Leahy. (2013). How much wind will be curtailed on the 2020 Irish power system. Renewable Energy , 544-553.

22. G.Strbac, M. Aunedi, D. Pudjianto, P. Djapic, F. Teng. (2012). Strategic Assessment of the Role and Value of Energy Storage Systems in the Uk Low Carbon Energy Future. London: Energy Future la, Imperial College London.

23. Gatzen, C. (2008). The economics of power storage. Munich: Oldenbourg Industrieverlag.

24. General Electric. (2011). GE FlexEfficiency* 50 Combined Cycle Fact Sheet. Retrieved January 09, 2015 from

http://www.ge.com/cn/energy/solutions/s5/FlexEfficiency50\%20Combined\%20Cycle\%20Power\%20Pla nt.pdf

25. H. Zhao, Q.i Wua, S. Huc, H.a Xu, C.s N. Rasmussen. (2015). Review of energy storage system for wind power integration support. Applied Energy, 137 (2015), 545-554.

26. Hummel F., Jakoby R., Stevens M. (2013). Combined Cycle Power Plants as ideal solution to balance grid fluctuations. PowerGen Europe. Viena.

27. I Vorushylo Lytvyn, N. J. Hewitt. (2013). Barriers to increased electricity interconnection between neighboring markets. 10th International Conference on the European Energy Market. Stockholm.

28. Market Monitoring Unit. (2010). Power Plant Cycling. Retrieved 2016 йил 09-January from http://www.allislandproject.org/

29. Mullane, A. (2009). IEA Wind Task 25 Storage Research. Energy Storage Seminar. Dublin: Energy Storage Seminar.

30. National Grid. (2014). UK Future Energy Scenarios. Retrieved 2015 йил 09-January from http://www.nationalgrid.com

31. Nyamdash B.,Denny E.,O'Malley M. (2010). The viability of balancing wind generation with large scale energy storage. Energy Policy , 7200-7208. 
32. O'Donnell, P. (2009). Investigation of large pumped storage on the All-island system. Energy Storage Seminar. Dublin: Electricity Storage Seminar.

33. P. Keatley, A. Shibli, N.J. Hewitt. (2013). Estimating power plant start costs in cyclic operation. Applied Energy, 111, 550-557.

34. P. Mastropietroa, , P. Rodillaa, , C. Batllea. (2015). National capacity mechanisms in the European internal energy market: Opening the doors to neighbours. Energy Policy , 82, 38-47.

35. Platts. (n.d.). Platts Energy Company. Retrieved January 09, 2015 from http://www.platts.com/

36. Probert, T. (2011). Fast starts and flexibility: Let the gas turbine battle commence. Power Engineering International .

37. R.K. Edmunds, Cockerill, T.J. Foxon, D.B. Ingham, M. Pourkashanian. (2014). Technical benefits of energy storage and electricity interconnections in future British power systems. Energy , 70, 577-587.

38. SEM Committee. (2014, December 19). DS3 System Services Procurement Design and Emerging Thinking. Decision paper. From http://www.allislandproject.org

39. SEM Committee. (2014). SEM Commitee decision on High Level Design. Retrieved January 09, 2015 from http://www.allislandproject.org/en/wholesale_overview.aspx?article=d3cf03a9-b4ab-44af-8cc0ee1b4e251d0f

40. SEM Committee. (2014). SEM Committee Decision on High Level Design. Impact Assessment. Retrieved January 09, 2015 from http://www.allislandproject.org/en/wholesale_overview.aspx?article=d3cf03a9b4ab-44af-8cc0-ee1b4e251d0f

41. Troy, N. (2010). Multi-mode Operation of Combined Cycle Gas Turbines with Increasing Wind Penetration. IEEE Transactions on Power Systems .

42. V. Bianco, F. Scarpa, L.A. Tagliafico. (2015). Long term outlook of primary energy consumption of the Italian thermoelectric sector: Impact of fuel and carbon prices. Energy, 87, 153-164

43. Xi. Luo, J. Wang, M.k Dooner, J. Clarke. (2015). Overview of current development in electrical energy storage technologies and the application potential in power system operation. Applied Energy , 5011536. 
Table 1. Forward-looking model validation results

\begin{tabular}{|c|c|c|c|c|}
\hline Validation parameter & Period & $\begin{array}{c}\text { Historical } \\
\text { average }\end{array}$ & Plexos model average & Difference, \% \\
\hline \multirow{2}{*}{$\begin{array}{c}\text { Total system costs } \\
(\mathrm{M} €)\end{array}$} & 2008 & 3,104 & 2,903 & $-6 \%$ \\
\cline { 2 - 5 } & 2009 subinterval & 979 & 936 & $-4 \%$ \\
\cline { 2 - 5 } & whole period & 4,083 & 3,839 & $-6 \%$ \\
\hline
\end{tabular}

Table 2. Overview of the modelling scenarios

\begin{tabular}{|c|c|c|c|c|}
\hline & \multirow[t]{2}{*}{ Scenario } & 2020 & $\begin{array}{c}2030 \\
\text { Slow Progress } \\
(\text { SP) } \\
\end{array}$ & $\begin{array}{c}2030 \\
\text { Rapid Progress } \\
\text { (RP) } \\
\end{array}$ \\
\hline & & 4.7 GW WPG & 5.8 GW WPG & 6.3 GW WPG \\
\hline \multirow{4}{*}{ 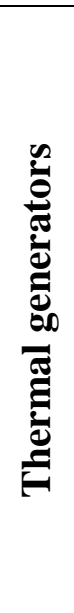 } & NIFG & $\begin{array}{l}\text { - Extant units still available } \\
\text { in } 2020 \\
\text { - Plus } 445 \mathrm{MW} \text { conventional } \\
\text { CCGT (1 unit) }\end{array}$ & \multicolumn{2}{|c|}{$\begin{array}{l}\text { - Extant units still available in } 2030 \\
\text { - Plus } 845 \mathrm{MW} \text { conventional CCGT } \\
(2 \text { units })\end{array}$} \\
\hline & $\mathrm{BaU}$ & NIFG + 300 MW OCGT & \multicolumn{2}{|c|}{ NIFG + 400 MW OCGT } \\
\hline & Advanced CCGT & \multicolumn{3}{|c|}{ NIFG + 400 MW Advanced CCGT } \\
\hline & $\begin{array}{c}\text { Advanced CCGT } \\
\text { minus }\end{array}$ & N/A & \multicolumn{2}{|c|}{$\begin{array}{l}\text { Advanced CCGT scenario minus } \\
1 \times 445 \text { MW conventional CCGT unit }\end{array}$} \\
\hline \multirow{4}{*}{ 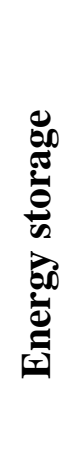 } & Storage 1 & \multicolumn{3}{|c|}{ NIFG + 100 MW Energy storage } \\
\hline & Storage 2 & \multicolumn{3}{|c|}{ NIFG + 200 MW Energy storage } \\
\hline & Storage 3 & \multicolumn{3}{|c|}{ NIFG + 300 MW Energy storage } \\
\hline & Storage 4 & \multicolumn{3}{|c|}{ NIFG + 400 MW Energy storage } \\
\hline
\end{tabular}

Table 3. Technical parameters of new thermal generators

\begin{tabular}{|l|l|l|l|}
\hline Property & OCGT & CCGT & CCGT Advanced \\
\hline
\end{tabular}




\begin{tabular}{|c|c|c|c|}
\hline Efficiency & $30 \%$ & $50 \%$ & $61 \%$ \\
\hline Fuel type & natural gas & natural gas & natural gas \\
\hline Min load, MW & 11 & 220 & 210 \\
\hline Max load, MW & 100 & 440 & $510(400)^{*}$ \\
\hline Ramp up rates, MW/min & 10 & 30 & 50 \\
\hline Synchronisation time when hot, hours & 0.1 & 2 & 0.5 \\
\hline Synchronisation time when warm, hours & 0.1 & 3.5 & 0.5 \\
\hline Synchronisation time when cold, hours & 0.1 & 5 & 1 \\
\hline
\end{tabular}

*Maximum capacity of advanced CCGT unit was downgraded to $400 \mathrm{MW}$ for the modelling comparison reasons as described earlier

Table 4. Fuel and carbon emissions prices implemented in Plexos 2020 and 2030 models

\begin{tabular}{|l|l|l|l|l|l|}
\hline Horizon & $\begin{array}{c}\text { Gas, } \\
€ / G J\end{array}$ & $\begin{array}{c}\text { Coal, } \\
€ / G J\end{array}$ & $\begin{array}{c}\text { Distillate, } \\
€ / G J\end{array}$ & $\begin{array}{c}\text { Oil, } \\
€ / G J\end{array}$ & $\begin{array}{l}\text { Carbon, } \\
€ / \text { tonne }\end{array}$ \\
\hline 2020 & 3.68 & 9.15 & 24.74 & 16.32 & 37 \\
\hline 2030 & 3.68 & 9.15 & 27.90 & 18.40 & 37 \\
\hline
\end{tabular}

Table 5. 2020 and 2030 SEM consumer demand forecast assumptions (Eirgrid, SONI, 2014), (SEM Committee, 2014)

\begin{tabular}{|c|c|c|}
\hline \multirow{2}{*}{ Region } & \multicolumn{2}{|c|}{ SEM } \\
\cline { 2 - 3 } & $\begin{array}{c}\text { Total } \\
\text { demand, } \\
\text { TWh, } \\
2020\end{array}$ & $\begin{array}{c}\text { Transmission } \\
\text { peak, GW, } \\
2020\end{array}$ \\
\hline 2020 & 38.5 & 7.0 \\
\hline 2030 & 43.2 & 7.8 \\
\hline
\end{tabular}

Table 6. Investment costs for the new thermal generators (DECC, 2013)

\begin{tabular}{|l|c|c|c|c|c|c|}
\hline Technology type & $\begin{array}{c}\text { Predevelopment costs, } \\
€ \text { 000/MW }\end{array}$ & $\begin{array}{c}\text { Construction costs, } \\
€ \text { 000/MW }\end{array}$ & $\begin{array}{c}\text { Economic } \\
\text { lifetime }\end{array}$ & $\begin{array}{c}\text { FO\&M, } \\
€ \text { 000/year }\end{array}$ & $\begin{array}{c}\text { Insurance, } \\
€ \text { 000 MW/year }\end{array}$ & $\begin{array}{c}\text { Connection and UoS charges, } \\
€ \text { 000/MW/yr }\end{array}$ \\
\hline CCGT Advanced* & 29 & 824 & 25 & 26 & 2.34 & 8.06 \\
\hline CCGT medium & 12 & 707 & 25 & 26 & 2.34 & 8.06 \\
\hline OCGT & 35 & 353 & 25 & 12 & 1.13 & 4.05 \\
\hline
\end{tabular}

*Capital costs for the flexible CCGTs are not announced yet. They were assumed to be equal to the CCGTs commissioning in 2020 following high cost scenario from the DECC Electricity Generation Costs report (DECC, 2013). 
Table 7. Investment costs for energy storage technologies (Gatzen, 2008), (Luo et al, 2015) (Zhao et al, 2015), (Strbac et al, 2012), (Deane et al, 2010)

\begin{tabular}{|l|l|l|l|l|l|}
\hline Technology & $\begin{array}{l}\text { Capital costs, } \\
€ 000 / \mathrm{MW}\end{array}$ & $\begin{array}{l}\text { Round trip efficiency, } \\
\%\end{array}$ & $\begin{array}{l}\text { FO\&M costs, } \\
€ \text { 000/MW year }\end{array}$ & $\begin{array}{l}\text { Insurance, } £ \\
\text { 000 MW/year }\end{array}$ & $\begin{array}{l}\text { Economic lifetime, } \\
\text { years }\end{array}$ \\
\hline Pumped-hydro Storage & $435-2,170$ & $70-85$ & 3.8 & 1.06 & 30 \\
\hline CAES & $650-750$ & 57 & 1.42 & 1.06 & 30 \\
\hline Redox batteries & $2,300-2,350$ & $70-85$ & 6 & 1.06 & $5-10$ \\
\hline Hydrogen plus fuel cells & $2,350-2,450$ & $32 *$ & 6 & 1.06 & $10-20$ \\
\hline
\end{tabular}

*The value represents electrical efficiency only

Table 8. Major economic characteristics of the future 2020 energy market scenarios

\begin{tabular}{|c|c|c|c|c|c|c|c|c|}
\hline Parameter & Units & NIFG & Storage 1 & Storage 2 & Storage 3 & Storage 4 & $\mathrm{BaU}$ & $\begin{array}{l}\text { Advanced } \\
\text { CCGT }\end{array}$ \\
\hline $\begin{array}{l}\text { Average spot } \\
\text { price }\end{array}$ & $€ / M W h$ & 83.83 & 83.14 & 82.72 & 82.87 & 82.26 & 83.62 & 82.62 \\
\hline $\begin{array}{l}\text { Total Energy } \\
\text { Market } \\
\text { System costs }\end{array}$ & $€, \mathrm{~m}$ & 3,528 & 3,499 & 3,484 & 3,477 & 3,454 & 3,523 & 3,470 \\
\hline $\begin{array}{l}\text { Total system } \\
\text { cost savings }\end{array}$ & $\begin{array}{c}(€, \mathrm{~m}) \\
\%\end{array}$ & & $\begin{array}{c}-29 \\
(-0.82 \%)\end{array}$ & $\begin{array}{c}-45 \\
(-1.26 \%)\end{array}$ & $\begin{array}{c}-51 \\
(-1.44 \%)\end{array}$ & $\begin{array}{c}-74 \\
(-2.11 \%)\end{array}$ & $\begin{array}{c}-5 \\
(-0.15 \%)\end{array}$ & $\begin{array}{c}-59 \\
(-1.66 \%)\end{array}$ \\
\hline
\end{tabular}

Table 9. System cost saving for the 2030 SEM simulation

\begin{tabular}{|c|c|c|c|c|c|c|c|c|c|}
\hline Parameter & Units & NIFG & Storage 1 & Storage 2 & Storage 3 & Storage 4 & BaU & $\begin{array}{c}\text { Advanced } \\
\text { CCGT }\end{array}$ & $\begin{array}{c}\text { Advanced } \\
\text { CCGT } \\
\text { minus }\end{array}$ \\
\hline $\begin{array}{c}\text { System } \\
\text { costs 2030 } \\
\text { SP }\end{array}$ & $€, \mathrm{~m}$ & 3,652 & 3,593 & 3,577 & 3,535 & 3,521 & 3,585 & 3,519 & 3,592 \\
\hline $\begin{array}{c}\text { System cost } \\
\text { savings, SP }\end{array}$ & $\begin{array}{c}€, \mathrm{~m} \\
(\%)\end{array}$ & & $\begin{array}{c}-59 \\
(-1.61 \%)\end{array}$ & $\begin{array}{c}-75 \\
(-2.05 \%)\end{array}$ & $\begin{array}{c}-117 \\
(-3.19 \%)\end{array}$ & $\begin{array}{c}-131 \\
(-3.59 \%)\end{array}$ & $\begin{array}{c}-67 \\
(-1.83 \%)\end{array}$ & $\begin{array}{c}-133 \\
(-3.63 \%)\end{array}$ & $\begin{array}{c}-60 \\
(-1.64 \%)\end{array}$ \\
\hline $\begin{array}{c}\text { System } \\
\text { costs 2030 } \\
\mathrm{RP}\end{array}$ & $€, \mathrm{~m}$ & 3,478 & 3,436 & 3,429 & 3,403 & 3,373 & 3,432 & 3,366 & 3,464 \\
\hline $\begin{array}{c}\text { System cost } \\
\text { savings, RP }\end{array}$ & $\begin{array}{c}€, \mathrm{~m} \\
(\%)\end{array}$ & & $\begin{array}{c}-42 \\
(-1.20 \%)\end{array}$ & $\begin{array}{c}-49 \\
(-1.42 \%)\end{array}$ & $\begin{array}{c}-75 \\
(-2.16 \%)\end{array}$ & $\begin{array}{c}-105 \\
(-3.03 \%)\end{array}$ & $\begin{array}{c}-46 \\
(-1.33 \%)\end{array}$ & -112 & $\begin{array}{c}-14 \\
(-3.23 \%)\end{array}$ \\
\hline
\end{tabular}


Table 10. Profitability of new thermal plant in the "Following market arrangements" group of scenarios

\begin{tabular}{|c|c|c|c|c|c|c|c|c|}
\hline & \multicolumn{2}{|c|}{$\begin{array}{c}2020 \text { profitability, } \\
€, 000 / \mathrm{MW}\end{array}$} & \multicolumn{3}{c|}{$\begin{array}{c}\text { 2030 RP profitability, } \\
€ \text { 000/MW }\end{array}$} & \multicolumn{3}{|c|}{$\begin{array}{c}\text { 2030 SP profitability, } \\
€, 000 / \mathrm{MW}\end{array}$} \\
\hline Unit & BaU & $\begin{array}{c}\text { Advanced } \\
\text { CCGT }\end{array}$ & BaU & $\begin{array}{c}\text { Advanced } \\
\text { CCGT }\end{array}$ & $\begin{array}{c}\text { Advanced } \\
\text { CCGT minus }\end{array}$ & BaU & $\begin{array}{c}\text { Advanced } \\
\text { CCGT }\end{array}$ & $\begin{array}{c}\text { Advanced } \\
\text { CCGT minus }\end{array}$ \\
\hline OCGT & $2.98-3.54$ & $2.11-3.18$ & $\begin{array}{c}7.96- \\
11.66\end{array}$ & & & $\begin{array}{c}4.48- \\
6.7\end{array}$ & & \\
\hline CCGT & 120.75 & 120.69 & $\begin{array}{c}73.39- \\
87.51\end{array}$ & $\begin{array}{c}71.96- \\
95.91\end{array}$ & 97.22 & $\begin{array}{c}82.22 \\
-\end{array}$ & $\begin{array}{c}72.66- \\
85.88\end{array}$ & 105.88 \\
\hline $\begin{array}{c}\text { CCGT } \\
\text { Advanced }\end{array}$ & & & & 113.31 & 127.70 & & 121.03 & 127.59 \\
\hline
\end{tabular}

Table 11. Profitability of new generation under the "Energy Storage" group of scenarios

\begin{tabular}{|l|c|c|c|c|}
\hline & $\begin{array}{c}\text { Energy } \\
\text { Storage 1 }\end{array}$ & $\begin{array}{c}\text { Energy } \\
\text { Storage 2 }\end{array}$ & $\begin{array}{c}\text { Energy } \\
\text { Storage 3 }\end{array}$ & $\begin{array}{c}\text { Energy } \\
\text { Storage 4 }\end{array}$ \\
\hline $\begin{array}{l}\text { Net profit/MW installed 2020 } €, \\
\text { 000/MW }\end{array}$ & 30.64 & 25.10 & 22.78 & 20.41 \\
\hline $\begin{array}{l}\text { Net profit/MW installed 2030 SP } €, \\
\text { 000/MW }\end{array}$ & 43.18 & 41.05 & 28.79 & 28.25 \\
\hline $\begin{array}{l}\text { Net profit/MW installed 2030 RP } €, \\
\text { 000/MW }\end{array}$ & 74.20 & 65.79 & 55.51 & 44.97 \\
\hline
\end{tabular}

Table 12. Fuel and carbon emissions prices for sensitivity analysis (implemented in Plexos 2030 model) (DECC, 2013)

\begin{tabular}{|l|c|c|c|c|c|}
\hline Scenario & $\begin{array}{c}\text { Gas, } \\
€ / \mathrm{GJ}\end{array}$ & Coal, $€ / \mathrm{GJ}$ & Distillate, $€ / \mathrm{GJ}$ & Oil, $€ / \mathrm{GJ}$ & Carbon, $€ /$ tonne \\
\hline High case & 2.782 & 5.235 & 15.50 & 10.22 & 30 \\
\hline Low case & 3.684 & 9.154 & 27.90 & 18.40 & 37 \\
\hline
\end{tabular}




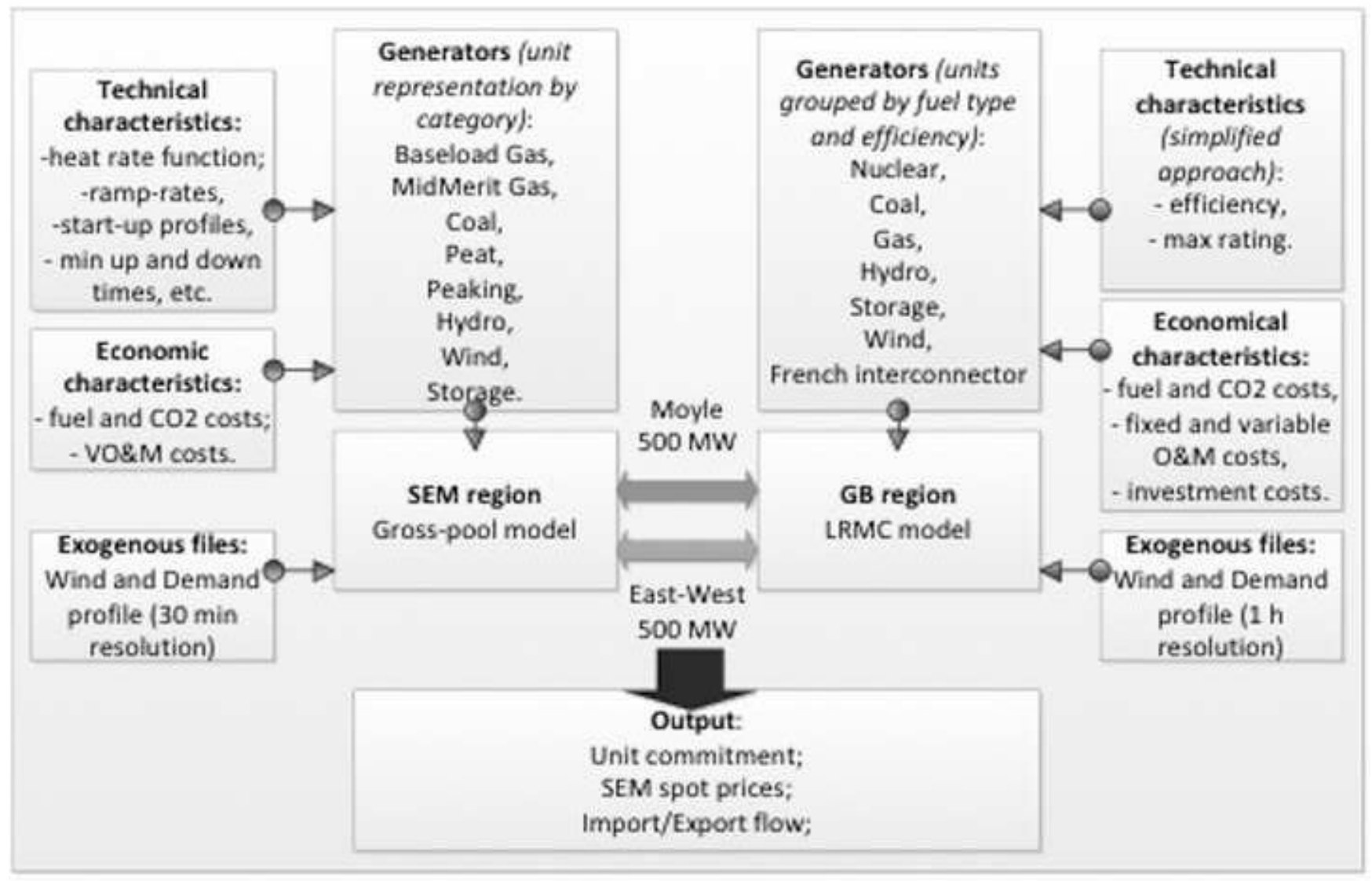

Fig. 1. Schematic representation of the SEM model in Plexos software

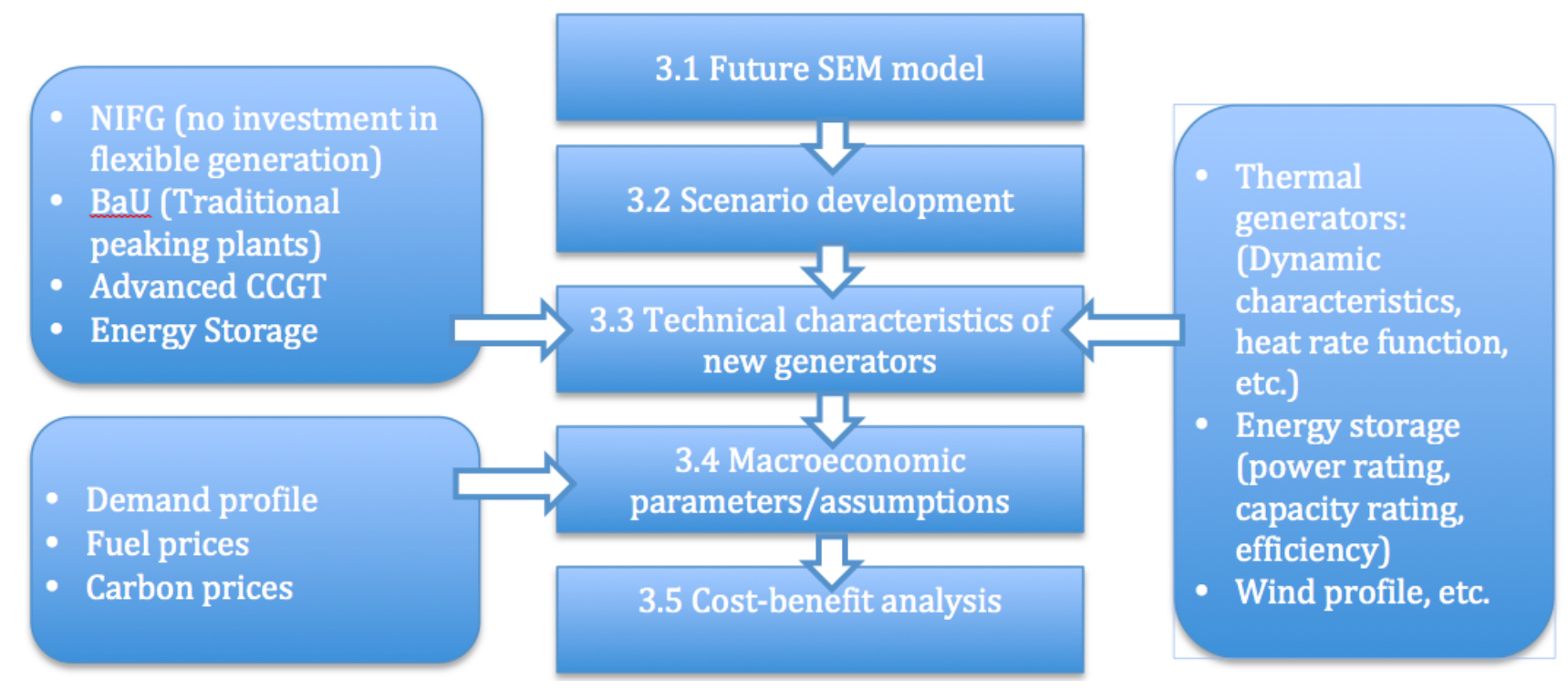

Fig. 2. Methodology overview diagram 


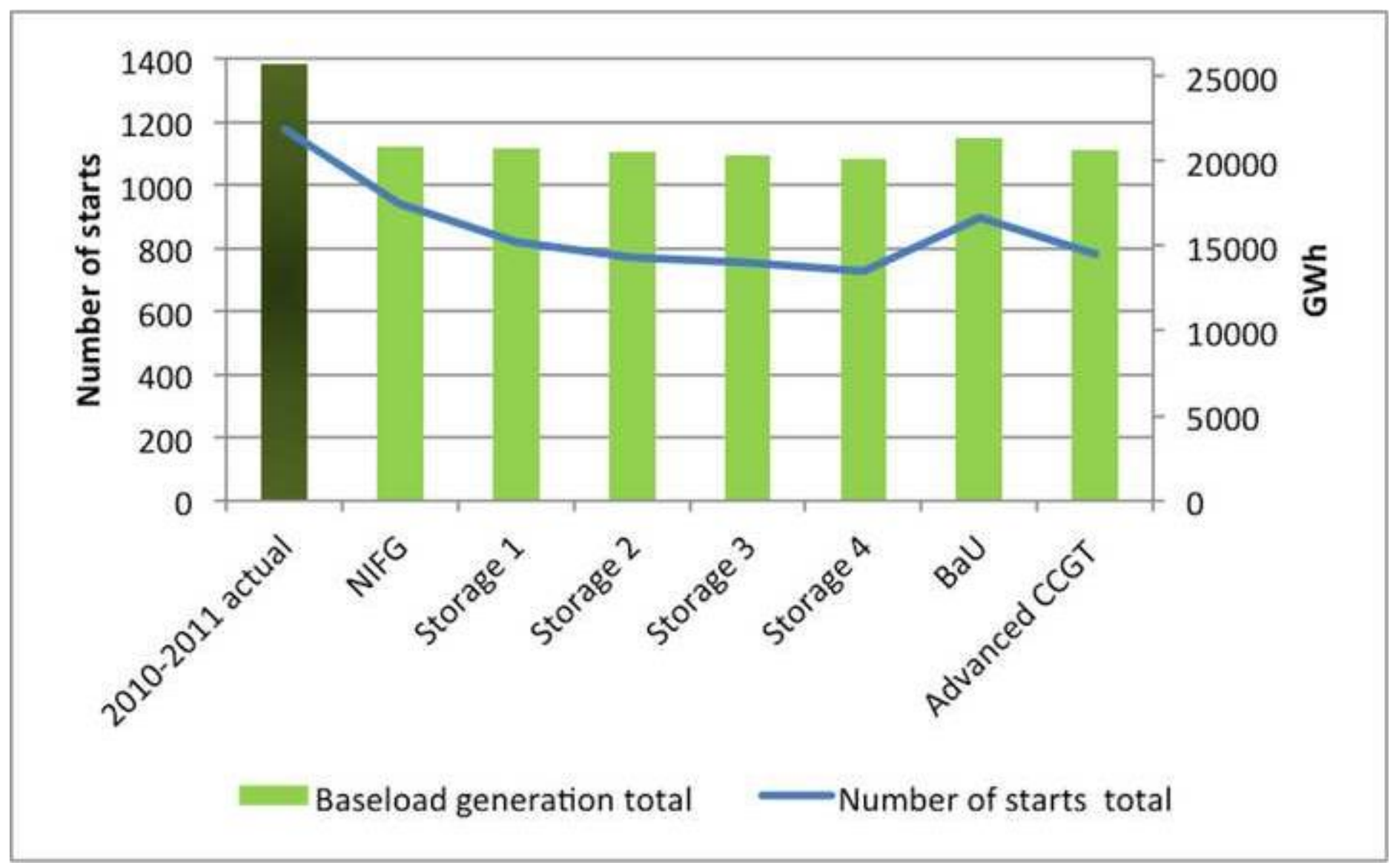

Fig. 3. Impact of VRE on operation of baseload and midmerit plants in 2020 in comparison with Nov 2010-Nov 2011 operation

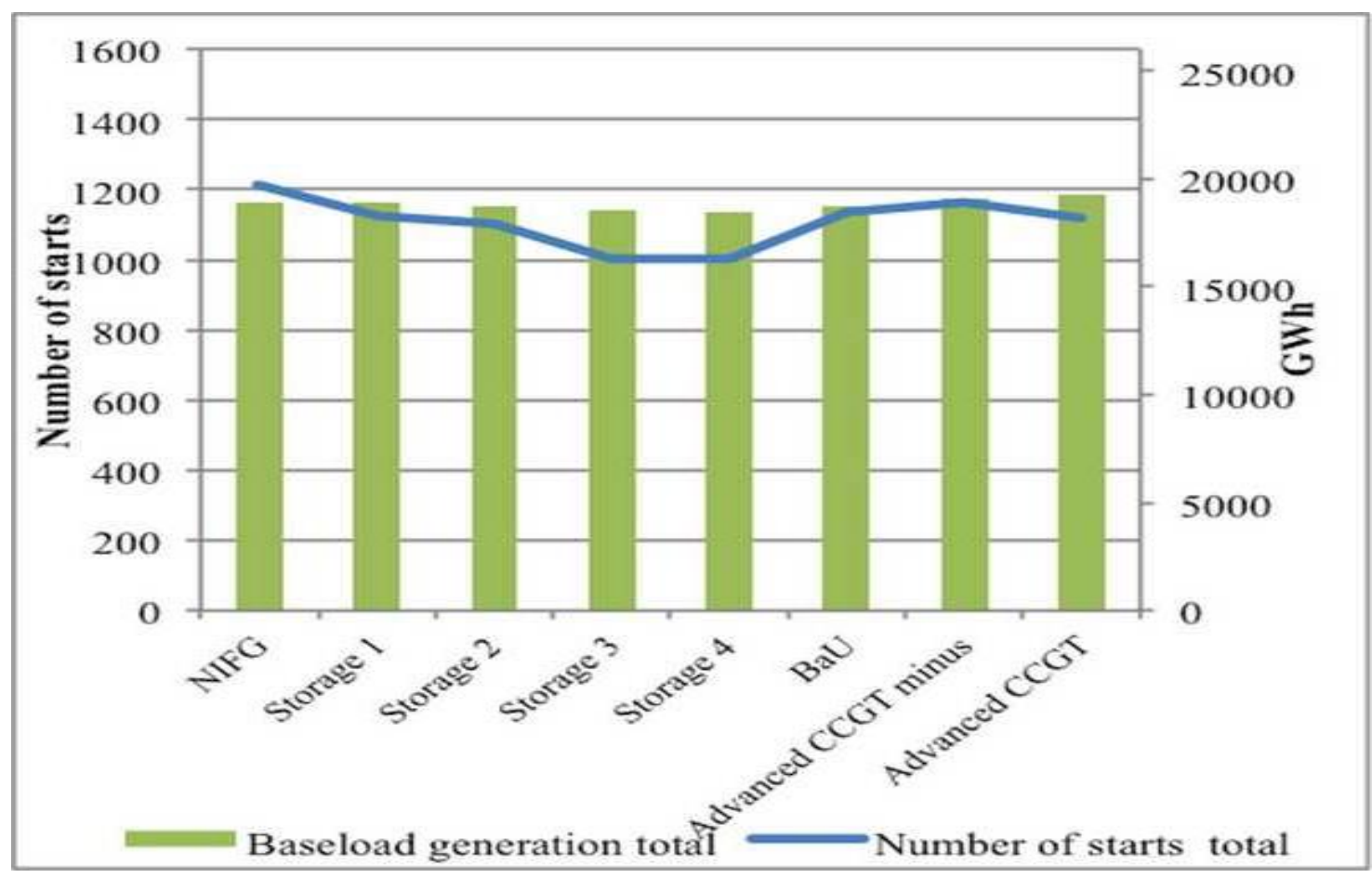

a)

Fig. 4. Impact of VRE on operation of baseload and midmerit plants in 2030 a) Slow Progress Scenario and b) Rapid Progress Scenario 


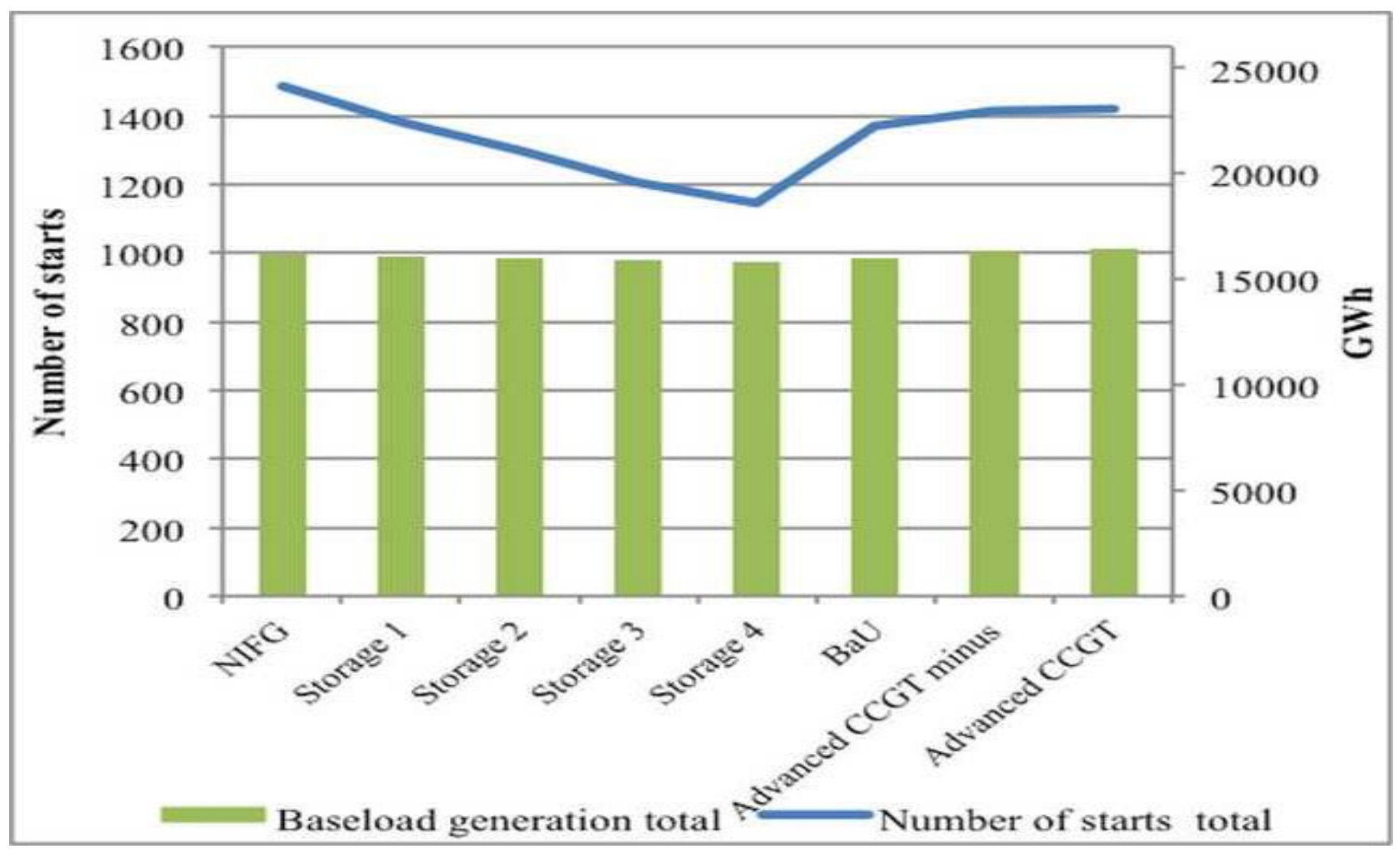

b)

Fig. 4. Impact of VRE on operation of baseload and midmerit plants in 2030 a) Slow Progress Scenario and b) Rapid Progress Scenario 


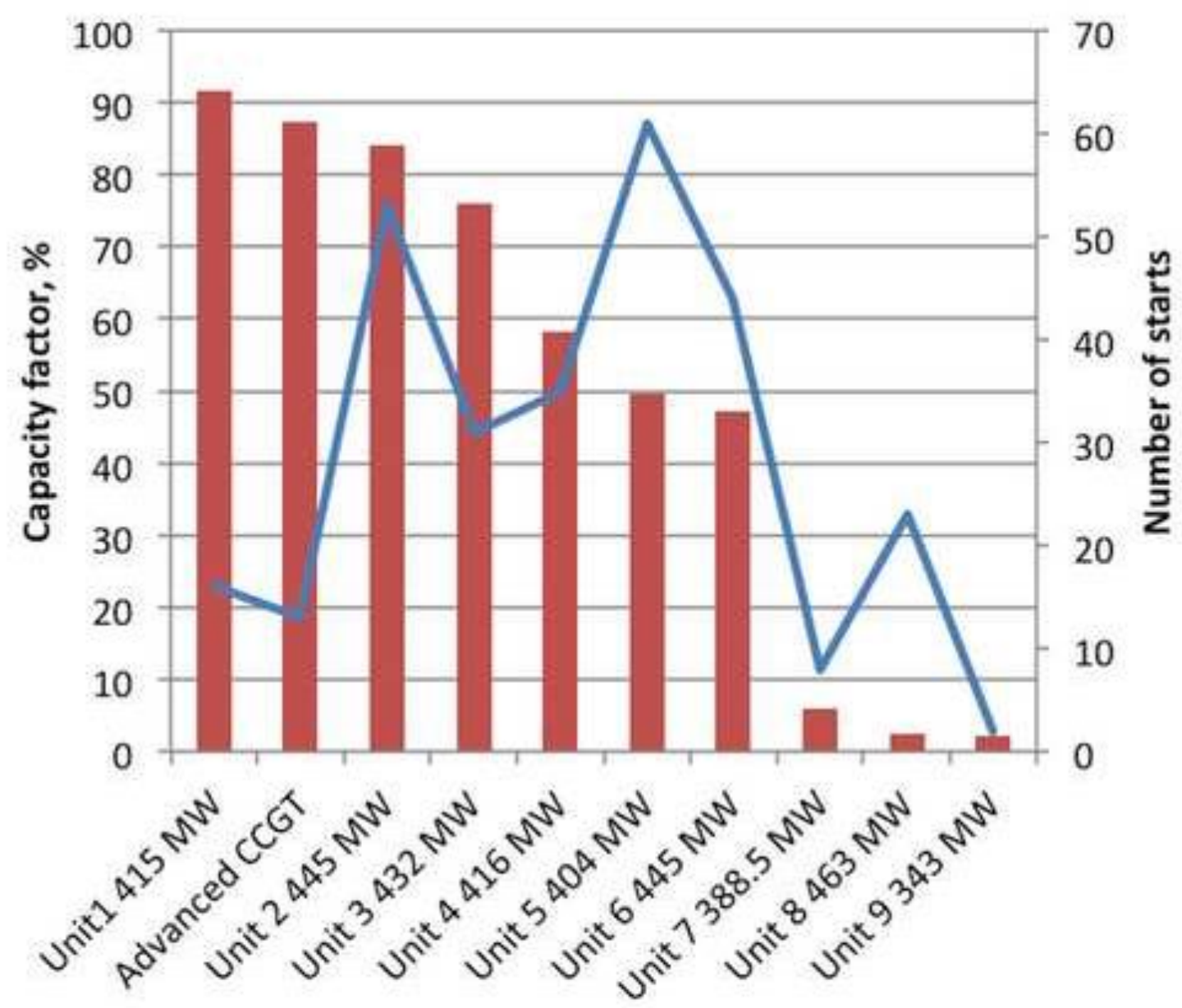

Capacity F

Number o

Fig. 5. Total generation and number of start-ups of baseload gas generators for the 2020 Advanced CCGT model

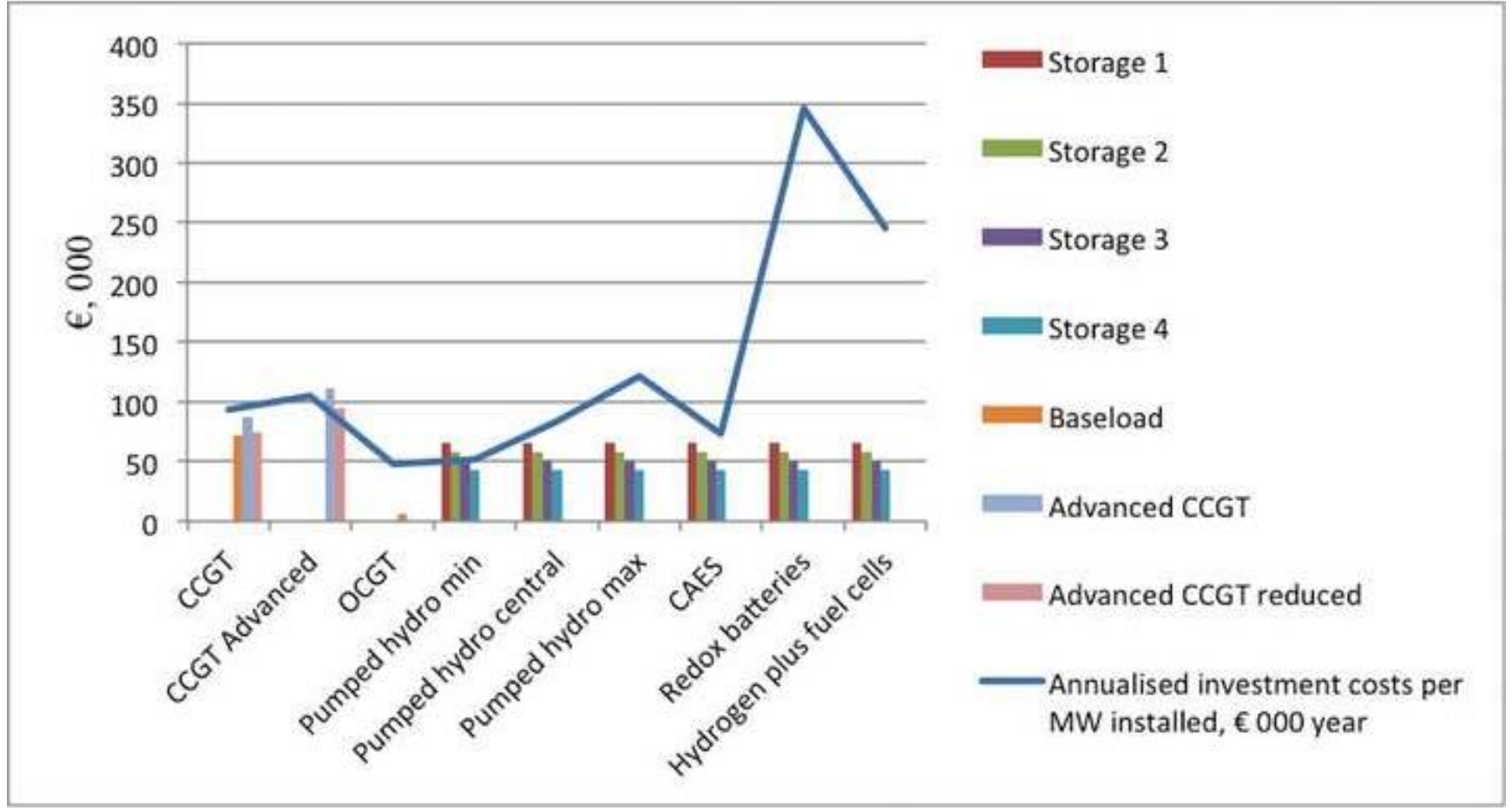

Fig. 6. Total annual profit received (column area) vs. annualised investment 
cost (line) per installed MW for 2020 group of scenarios

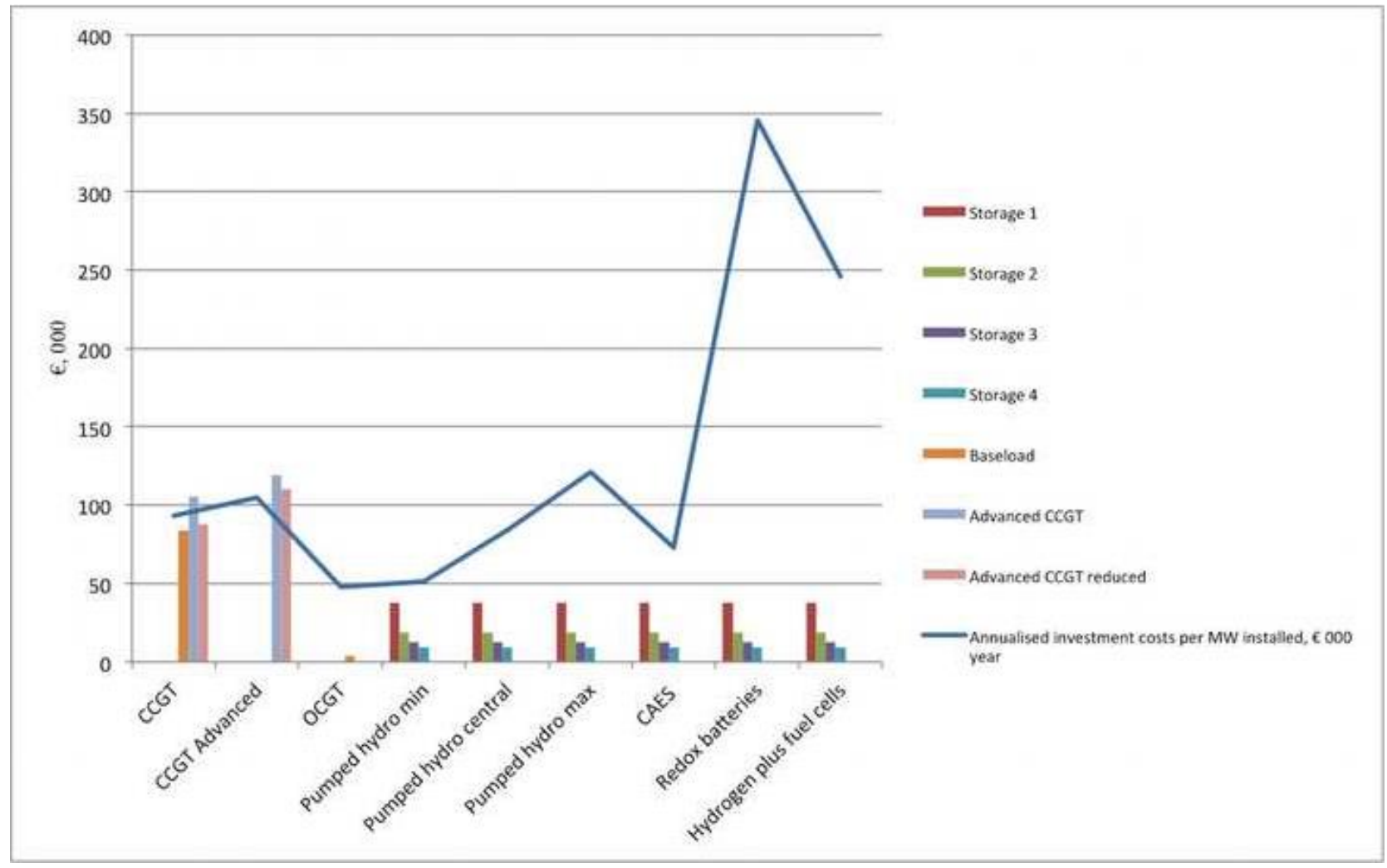

a)

Fig. 7. Total annual profit received (column area) vs. annualised investment cost (line) per installed MW for 2030 group of scenarios a) Slow Progress scenario b) Rapid Progress scenario 


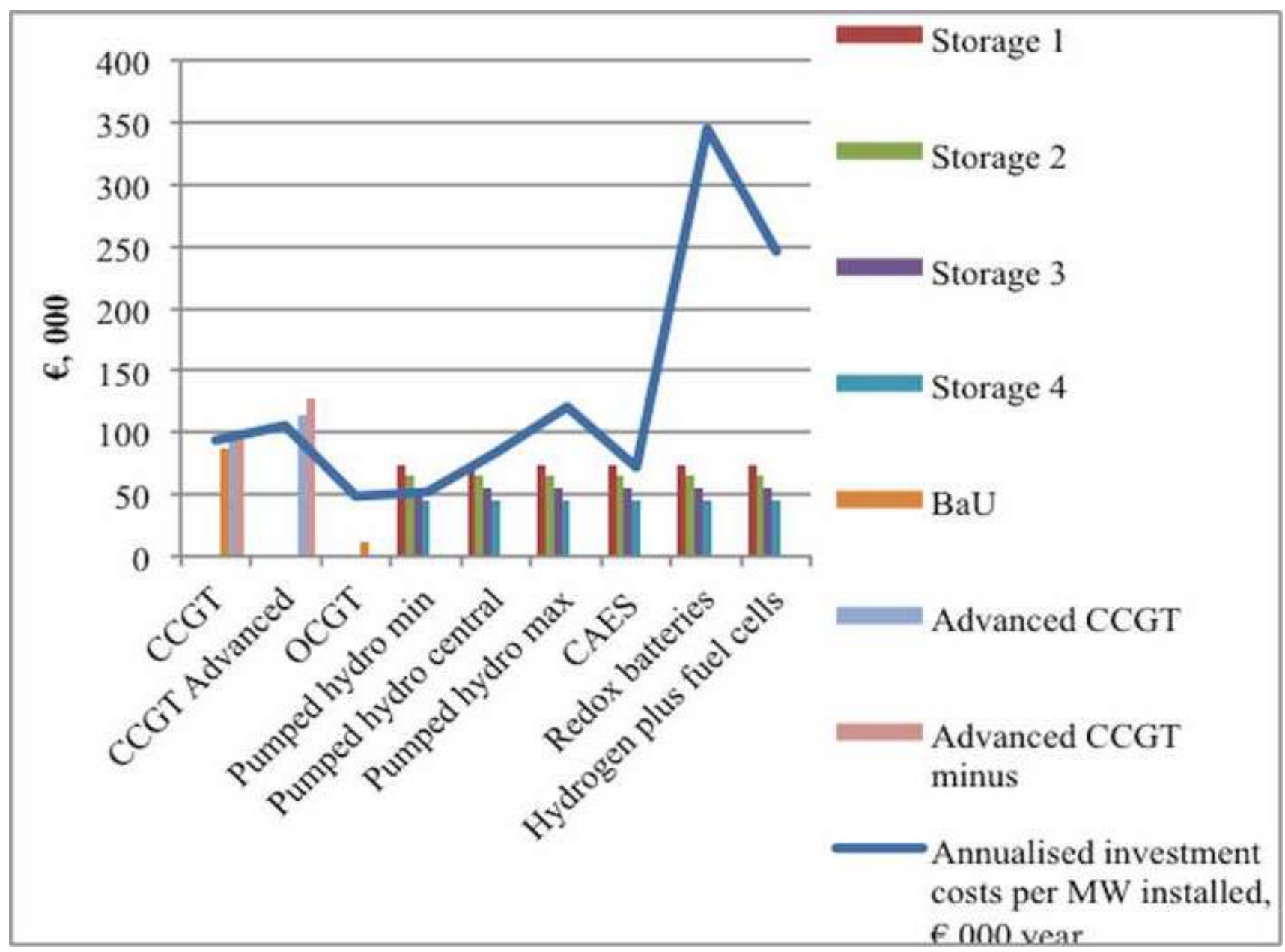

b)

Fig. 7. Total annual profit received (column area) vs. annualised investment cost (line) per installed MW for 2030 group of scenarios a) Slow Progress scenario b) Rapid Progress scenario 


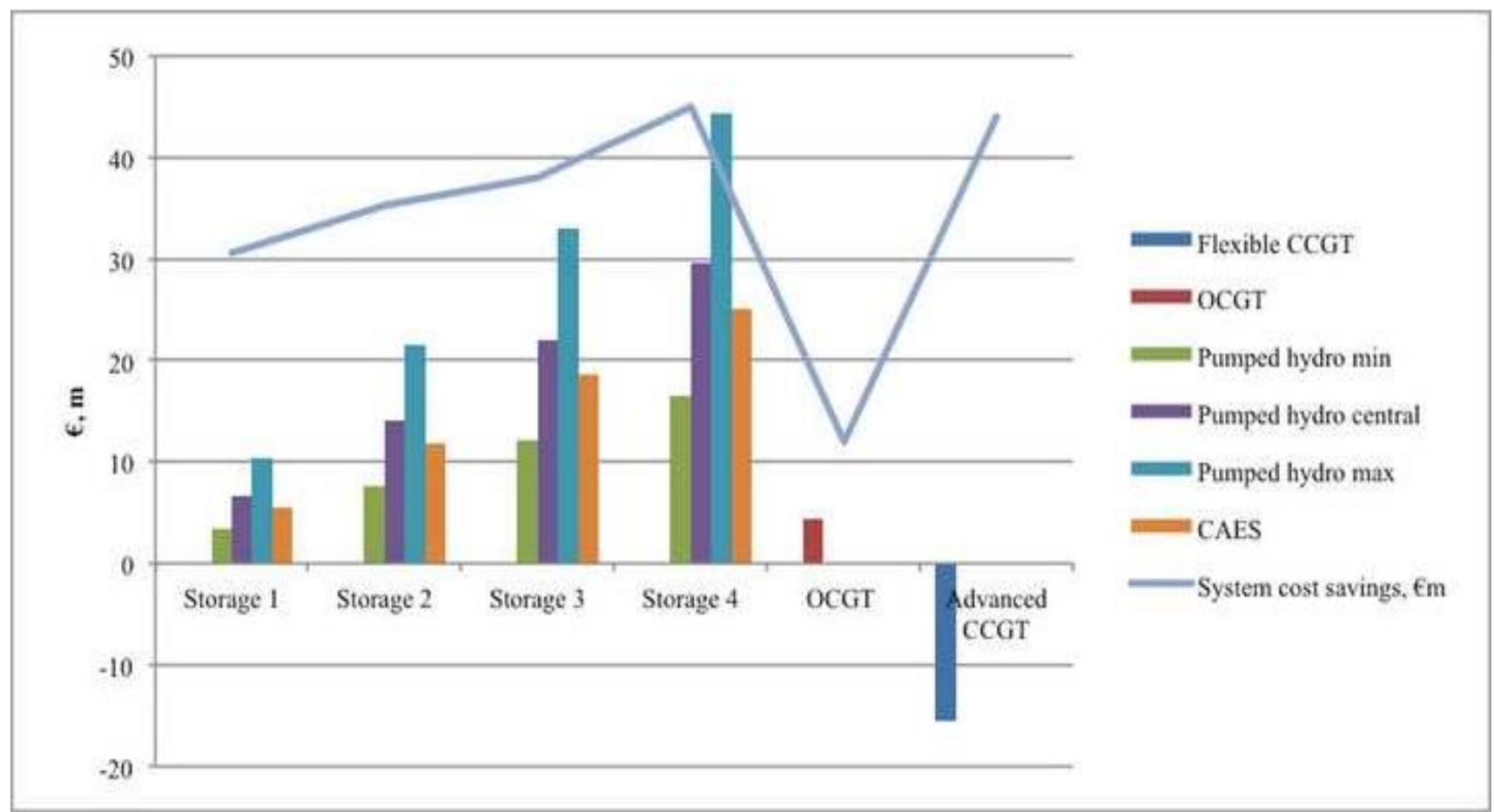

Fig. 8. Cost-benefit analysis of proposed flexible generators: deficit in recovering annualised investment and operation costs vs. total system saving costs for 2020 simulated SEM

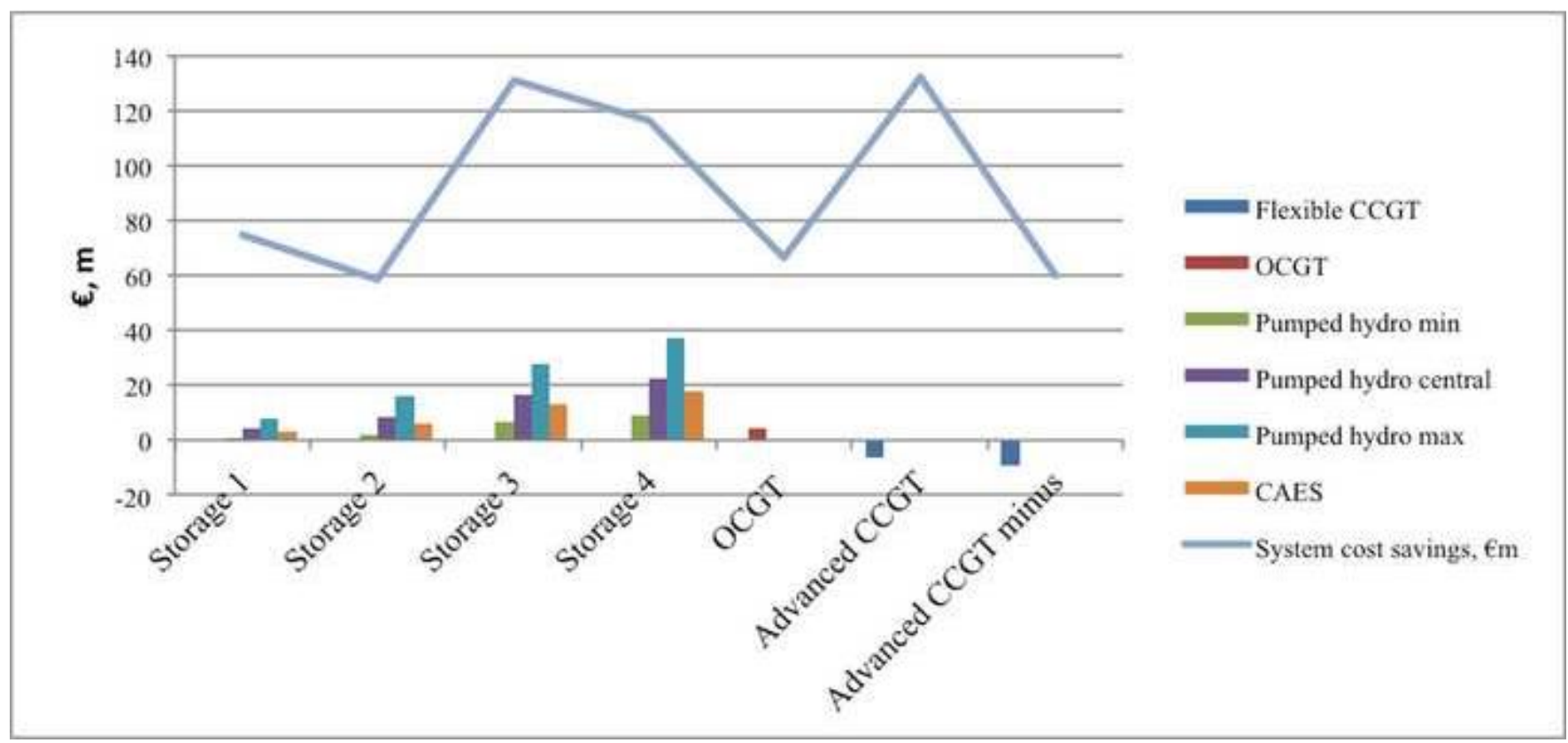

Fig. 9. Cost-benefit analysis of proposed flexible generators: deficit in recovering annualised investment and operation costs vs total system saving costs for 2030 Slow Progression scenario 


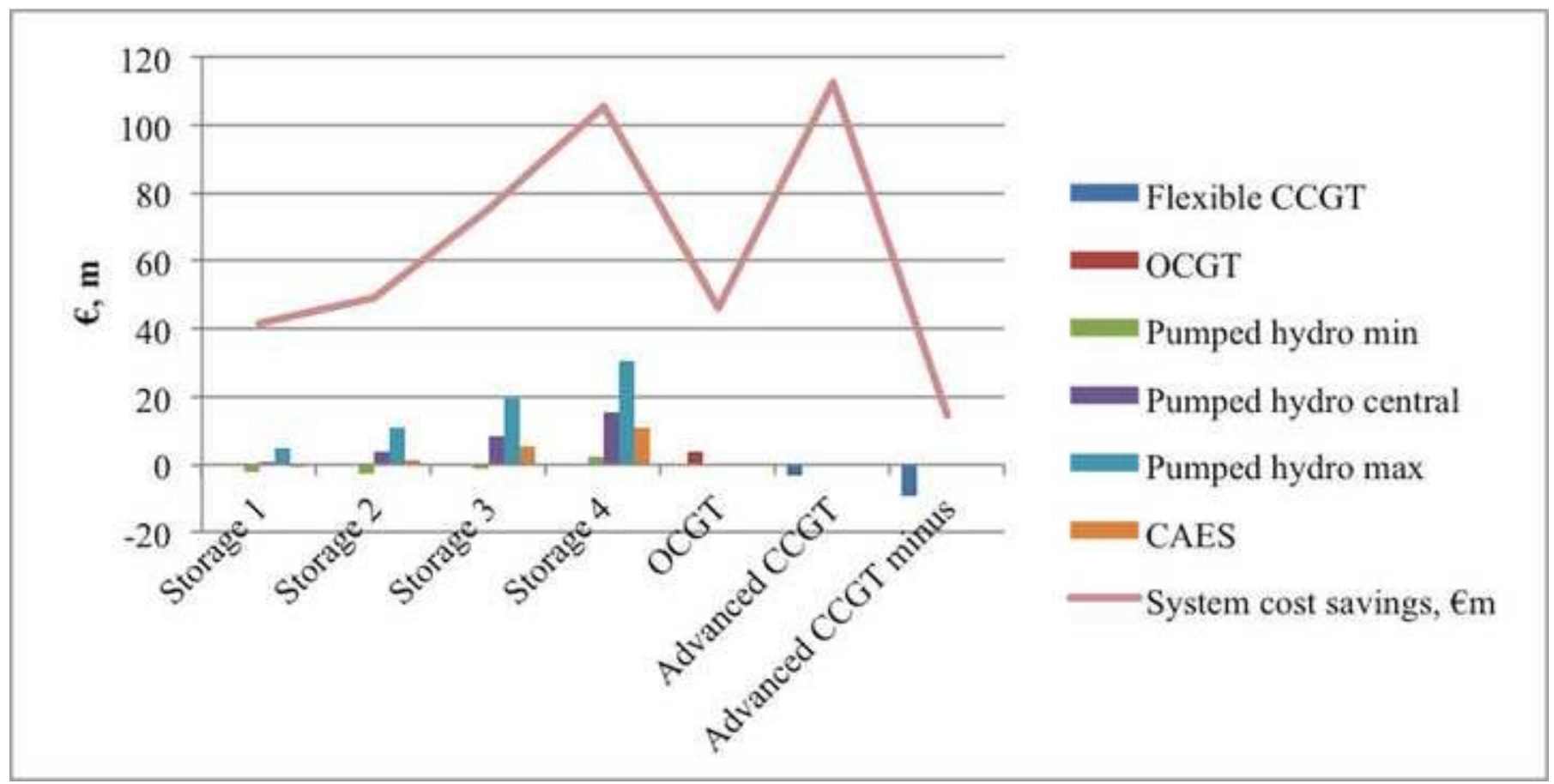

Fig. 10. Cost-benefit analysis of proposed flexible generators: deficit in recovering annualised investment and operation costs vs total system saving costs for 2030 Rapid Progress scenario

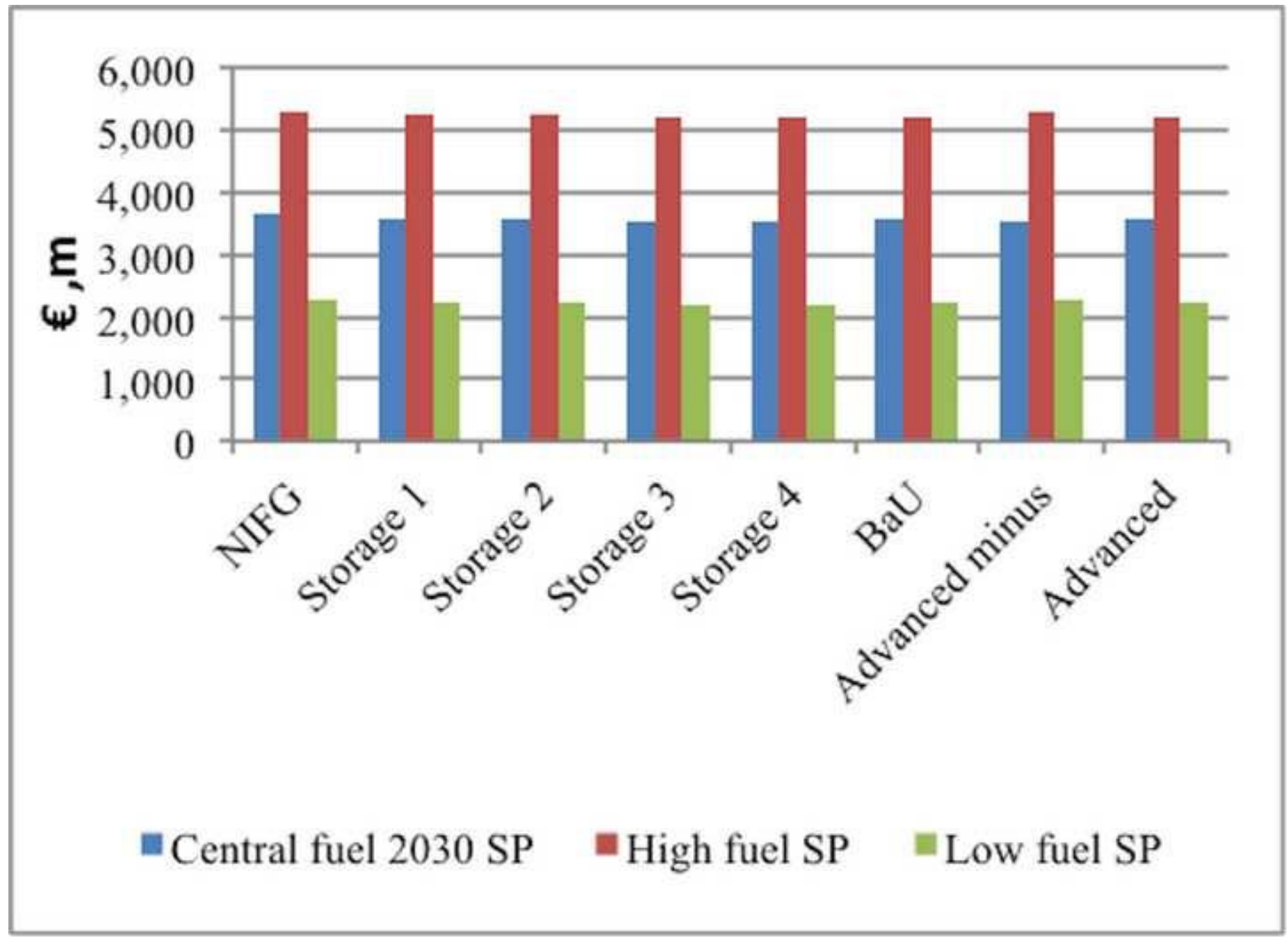


a)

Fig. 11. Changes in total energy market value under high and low fuel price scenarios a) Slow Progress scenario, b) Rapid Progress scenario

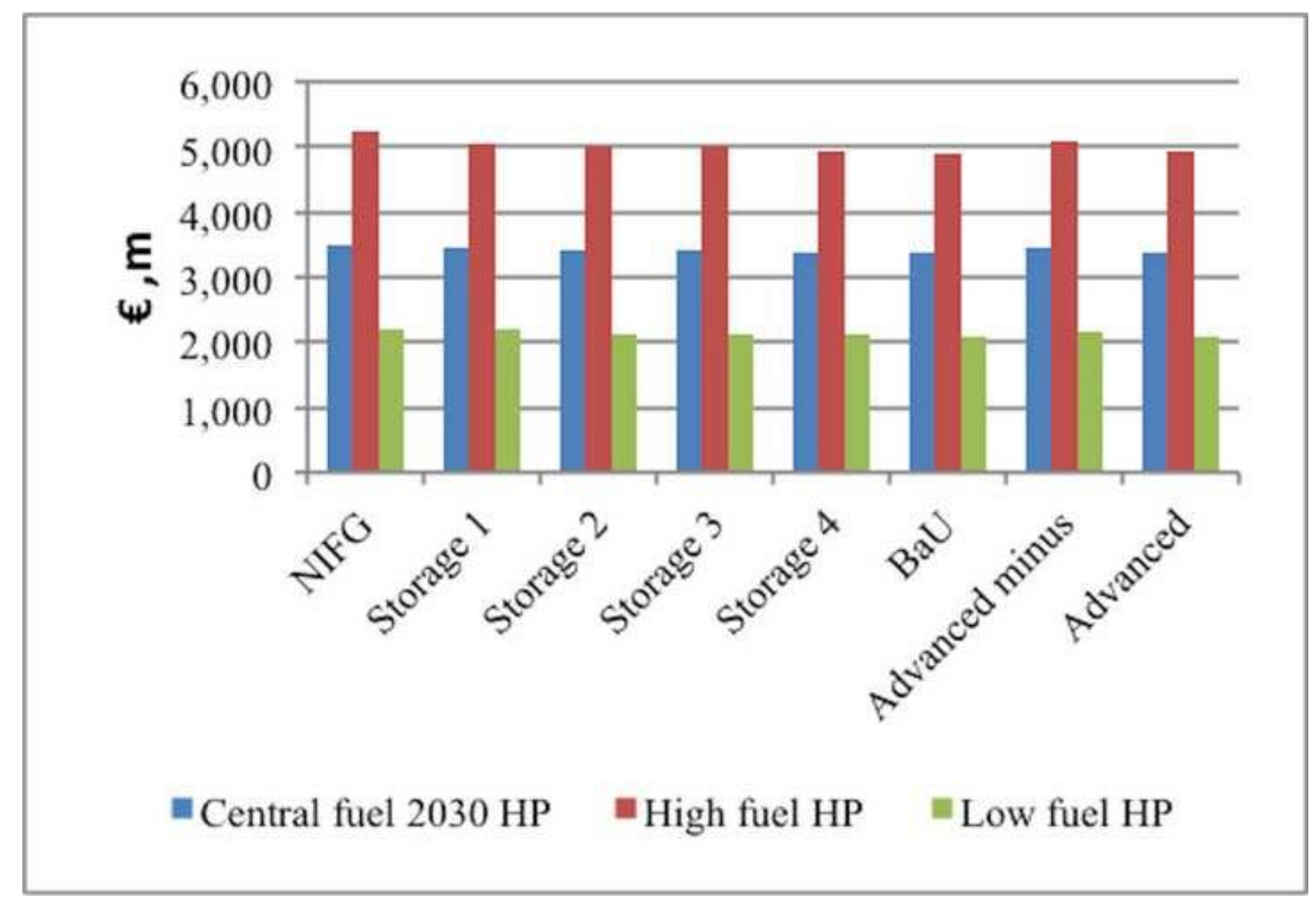

b)

Fig. 11. Changes in total energy market value under high and low fuel price scenarios a) Slow Progress scenario, b) Rapid Progress scenario 


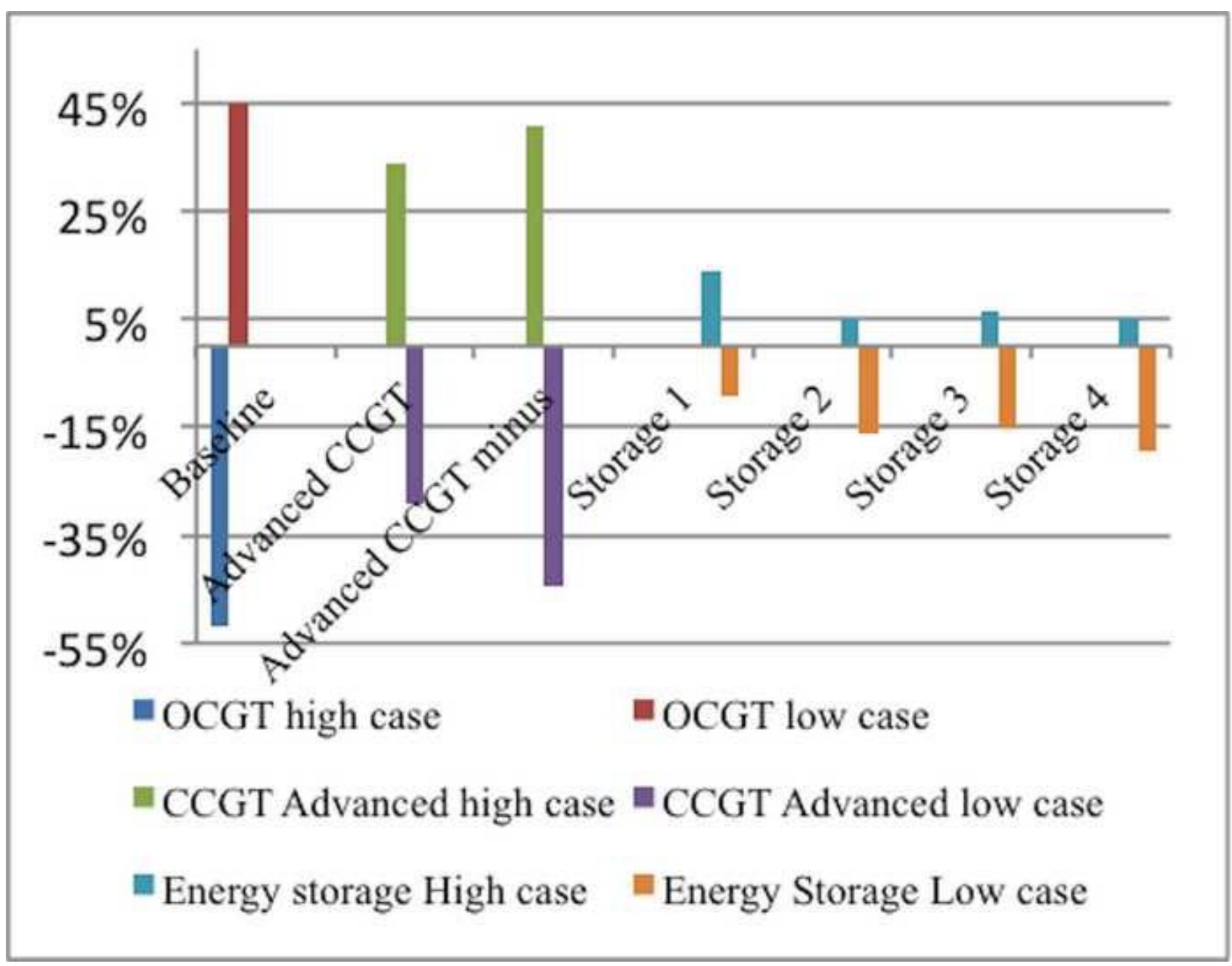

\section{a)}

Fig. 12. Changes in profitability (via infra-marginal rent) of flexible generators under high and low fuel price scenarios a) Slow Progress scenario, b) Rapid Progress scenario 


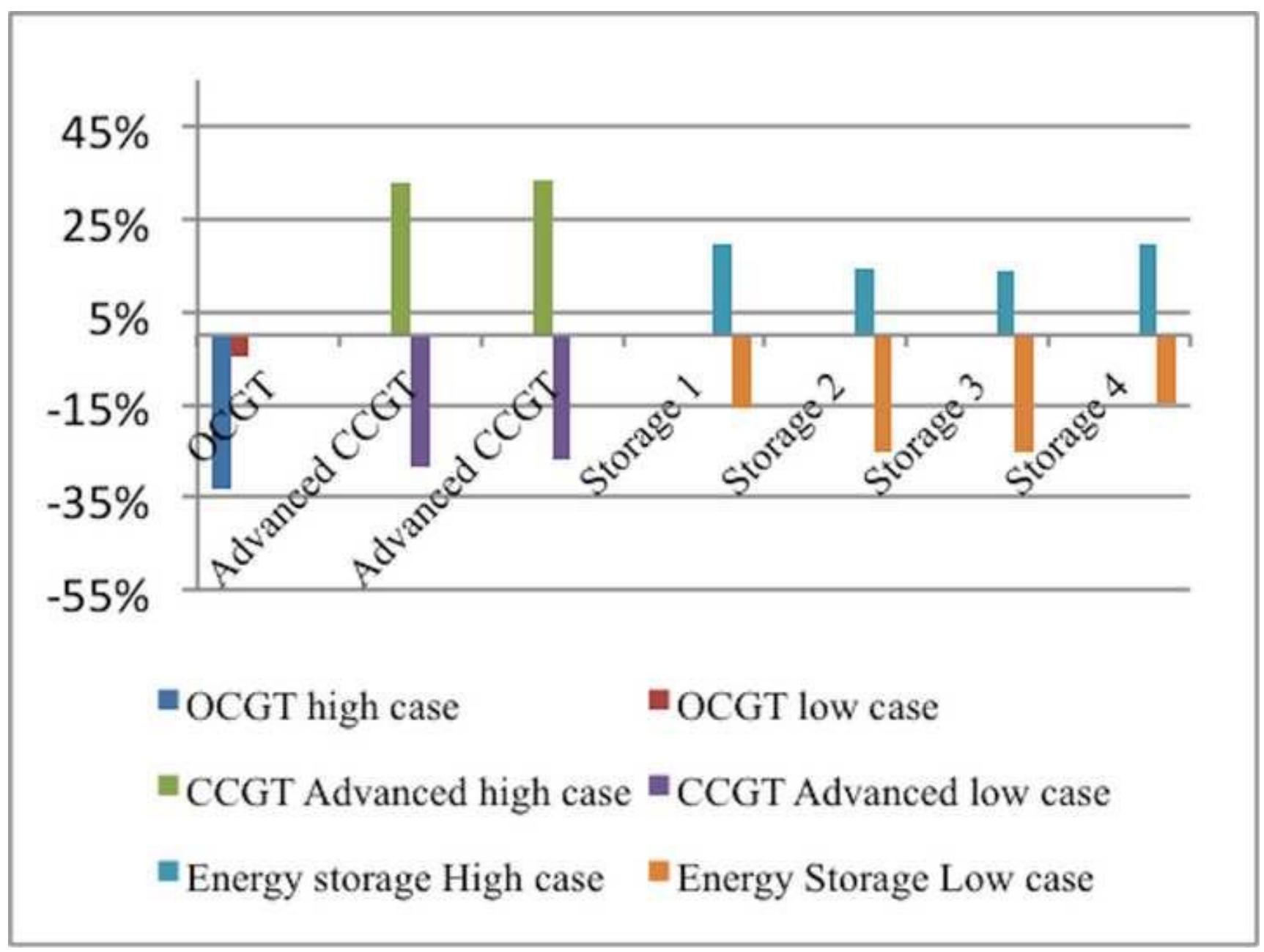

b)

Fig. 12. Changes in profitability (via infra-marginal rent) of flexible generators under high and low fuel price scenarios a) Slow Progress scenario, b) Rapid Progress scenario 